\title{
A Multi-Objective Approach for Determining Optimal Air Compressor Location in a Manufacturing Facility
}

\author{
Joel Zahlan ${ }^{\mathrm{a}}$, Shihab Asfour ${ }^{\mathrm{a}, *}$ \\ ${ }^{a}$ Department of Industrial Engineering, University of Miami, Coral Gables, Fl 33146, USA \\ *Corresponding author. Tel.:+1 3052842408; fax: +1 3052844792; Mobile: +1 3056077676. \\ Email addresses: j.zahlan@umiami.edu (J.Zahlan), sasfour@miami.edu (S.Asfour).
}

\begin{abstract}
Determining the optimal location of an air compressor in a manufacturing facility is a challenging problem that can offer significant energy savings. A novel simulation-optimization model is proposed to increase energy efficiency in a facility by determining optimal air compressor location. The optimization strategy is based on an objective function that minimizes the total energy consumption of the air compressor-hence, the energy cost for the facilitywhile considering the user's preference for the air compressor location. The proposed mathematical model first integrates the facility's characteristics based on user inputs, divides the facility into zones, and generates a rectilinear zone-to-zone distance matrix within the facility. The user location preference is incorporated into the proposed model via a five level userpreference index, assigned using preferential locations as suggested by twenty-two experienced facility managers. A sensitivity analysis is conducted to determine the relationship between the selected user preference level and the resulting energy consumption at each location in the facility. A simulation-driven analysis is performed using a real-life facility layout and typical compressed air equipment with corresponding nameplate data. In order to investigate and demonstrate the effectiveness of the proposed approach, the derived optimal zones are compared with five zones, including the most energy efficient zone, least energy efficient zone, and three other zones selected at random. The results of our study reveal that the proposed method
\end{abstract}


achieves significant energy reductions while maintaining the user's desired air compressor location.

Keywords: Compressed-Air System; Energy Efficiency; Location Optimization; Air Leakage Reduction; Pressure Drop Reduction; User Preference; Sensitivity Analysis; Simulationoptimization

\section{Introduction:}

Compressed air is often regarded as the fourth utility, and is one of the most critical applications in production and process environments $[1,2]$. Seventy percent of all manufacturing facilities in the United States (U.S) rely on compressed air systems, and in many cases, failure of these systems leads to the shutdown of their entire manufacturing process [3-5].

Compressed air accounts for approximately $10 \%$ of total industrial-energy use in the U.S, resulting in a staggering consumption of 90 billion kilowatt hour $(\mathrm{kWh})$ per year $[4,6,7]$. Furthermore, the total installed power capacity of compressed air systems in the U.S is estimated at more than 17 million horsepower [8], accounting for about 16\% of the industrial motor system energy use [9]. However, a well-designed compressed air system is only about $11 \%$ efficient [2] with some estimates stating that poorly designed systems account for up to $\$ 3.2$ billion in wasted utility payments in the U.S each year [10]. This inefficiency, combined with the fact that compressed air is the most expensive form of energy to deliver (Fig. 1 [11]), makes it critical for manufacturing facilities to seek to optimize compressed air energy efficiency and reduce cost.

In 2010 the U.S Energy information Administration (EIA) conducted a Manufacturing Energy Consumption Survey (MECS) of 15,500 manufacturing facilities in the U.S [12]. The data gathered from this survey was analyzed and a Manufacturing Energy and Carbon Footprint document illustrated the findings. This data shows that 14,064 TBtu is used in onsite energy at manufacturing facilities in the U.S. Of this $78 \%$ is Fuel (Natural Gas, Byproducts, Coal, etc.), $17 \%$ is Electricity, and 5\% is Steam. Of the total energy use, 2012 TBtu is used by machine drive (compressed air, pumps, fans, etc.) and of this 17\% or 341 TBtu accounts for Compressed Air. Furthermore $23 \%$ of total electrical consumption to machine drives in manufacturing facilities is consumed by air compressors [13]. According to the Energy and Carbon Footprint document, of the 341 TBtu consumed by the air compressor systems, $87.7 \%$ or 299 TBtu is 
written off as losses, making compressed air the least efficient machine-drive system in the survey.

This further illustrates the importance of optimizing air compressor systems in manufacturing facilities. Unfortunately, compressed air systems are one of the least understood processes in most manufacturing facilities $[14,15]$, mainly due to the widespread misconception that compressed air is inexpensive.

Fig 1. Cost of Energy Delivery Modes [11]

The energy associated with operating a compressed air system accounts for the largest cost to the user, often exceeding the initial cost of the compressor by up to five times over its lifespan $[8,16-20]$. Sometimes this cost accounts for up to $70 \%$ of the total electric bill in manufacturing facilities $[14,21,22]$. These figures point out that by implementing energy conservation measures, facilities can experience substantial energy and cost savings.

The U.S Department of Energy (DOE) states that over $50 \%$ of industrial facility's compressed air systems harbor large energy opportunity savings with relatively short payback periods [4, 23]. Energy savings from compressed air system improvements can range from 20$60 \%$ of electrical consumption, resulting in thousands, or even hundreds of thousands of dollars in potential annual savings $[4,24]$. Some of these compressed air efficiency measures include reducing leaks, matching supply with demand, reducing pressure settings, reducing average inlet temperature by using outside air, improving air distribution systems, and optimizing air compressor location. Fig. 2 illustrates some energy savings opportunities present in air compressor systems. As it can be seen, air leaks and air compressor system optimization account for the two largest losses in compressed air systems [25].

Fig.2. Energy Savings Opportunities in Air Compressor Systems [25]

Furthermore, studies suggest waste heat can also account for between 50-90\% of compressed air energy losses. With newer and more efficient motors on the market, the motor efficiency of the air compressor can be improved 2-8\% over most existing air compressors [2729]. The energy wasted in a poorly designed and maintained compressed air system can account for up to $50 \%$ of the energy used by the air compressor and it is believed that half of all these 
losses can be saved through proper system design and energy conservation measures [22]. In this paper the authors propose an optimization model that minimizes the distance compressed air must travel to high demand and high pressure locations in a facility, to reduce pressure drop and air leaks in the system, and improve the overall performance of the system.

The location of the air compressor in a facility plays a critical role in ensuring an energy efficient air compressor system. By optimizing the air compressor location, the distance to the highest demand and pressure zones is minimized, total pressure drop and number of air leaks is reduced, and compressed air distribution system (piping) is improved. According to Scott Foss, President of Plant Air Technology, "The concept design or redesign [of air compressor systems] should be to minimize the highest amount of air mass or volume of air and the distance that the air must flow to support any part of the system from supply to demand [2]”. In essence, the goal is to get the compressed air from the supply side to the demand side in the most efficient and cost effective manner to minimize losses in the system (air leaks and pressure drop).

The rate of pressure drop in a system is directly correlated to the distance compressed air must travel to air demand areas. Poorly designed air compressor systems can experience up to a $60 \%$ drop in pressure at the point of use of air $[22,29]$. Corrective actions must be taken on the air compressor system to improve pressure drop across the system.

Air leaks are the single greatest cause of energy loss in manufacturing facilities with compressed air systems and account for $20-50 \%$ of compressed air losses [14, 29, 30]. The majority of air leaks occur in Air leaks, occur at the joints, flange connections, elbows, reducing bushes, sudden expansions, valve systems, filters, hoses, check valves, relief valves, extensions, and the equipment connected to the compressed-air lines [29]. The amount of air lost to leaks is dependent on the line pressure of the pipe and the temperature of the air at the point of the leak [29].By minimizing distance to the highest pressure and volume locations, the goal is to minimize the number of joints in piping and the distance air must travel to the highest pressure and volume equipment.

There are many research articles and journal publications that describe the energy savings potential and recommend energy saving strategies for compressed air systems. Most of these publications discuss the importance of air compressor location and placement, however none of 
these actually measure the savings potential of optimizing air compressor location, and the resulting efficiency gain from doing so. Journal papers written by D. Kaya et al., Mark D'Antonio et al, R. Saidur et al., give an overview of compressed air conservation measures including air leak and pressure drop reduction, complete with analysis, potential energy and cost savings of minimizing these losses. However none quantify the effect air compressor location has on energy cost and losses. [22, 29, 31]. Compressed Air and Gas Handbook [1], The Compressed Air Industry Sourcebook, published by the DOE [32] and the Compressed Air Challenge Group (CAC) all suggest that pressure drop and air leaks are important for optimal system design. They indicate that distance to air compressor demand is important, and introduce equations for calculating air leaks and pressure drop that suggest loses have a linear correlation to distance.

With respect to air distribution and air compressor optimization, Kaeser Compressor's Designing your Compressed Air System states that it is essential to reduce the distance that air must travel, and discusses the importance in minimizing pressure drop and air leaks in the system, however there is no suggestion on potential savings [33]. Furthermore, R.S. Foss, The Compressed Air and Gas Institute (CAGI), CAC and the DOE all explain that minimizing the distance of compressed air to the highest demand locations is the key in creating an optimal distribution system and reducing energy costs [2, 32, 34]. Looking at information provided by the journal papers and texts listed above, as well as the authors' experience visiting over 280 manufacturing facilities in Florida and conducting dozens of comprehensive air compressor audits, it is clear that the location of air compressors in manufacturing facilities plays a critical role in the overall optimization of the air compressor system.

As illustrated above, there have been many journal papers and articles that talk about the importance of distance of the air compressor to demand regions in the facility; however none have attempted to measure the energy savings associated with optimizing the air compressor location and the effect location has on energy usage. The current decision making process for air compressor location is non-scientific and based heavily on availability of space and convenience of installation. This has forced users to size their compressors well above the required air compressor capacity so as to account for the losses in leaks and pressure drop due to the inefficient design. Manufacturer's guides on air compressor sizing show that 25-30\% more capacity is added as a factor of safety to make up for the unknown losses $[33,35]$. In this paper 
we provide a novel mathematical formulation to model the Compressor Location Problem and propose a simulation-optimization approach to quantify and minimize the distance compressed air must travel to the highest demand areas while considering the users preference for location. This will in turn minimize the air leaks and pressure drops that occur in the system while improving air distribution. The proposed model will also allow the user to assign a level of preference to each location, hence factoring in the users preference. Finally a sensitivity analysis is conducted to see the relationship between the energy consumption of the air compressor and the user's location preference. The goal of the research is to display the effect location has on the energy consumption of the air compressor, to quantify the losses that occur as the air compressor is put in each zone, and to allow for the correct sizing of the air compressor, all of which will ultimately reduce the energy costs associated with running air compressors in manufacturing facilities.

\section{Proposed Simulation-Optimization Model Development:}

The key to finding the optimal air compressor location in a facility is to first identify and prioritize the determinants for air compressor energy consumption and the user's location preference. Consequently, a mathematical model is developed to determine the optimal air compressor location in a facility that minimizes total energy consumption while considering the user's location preference. The following sections discuss the development of the proposed multi-objective function and its derivatives.

\subsection{Mathematical Formulation of the Proposed Model}

The proposed model has two goals: (1) minimizing the total energy consumption of the air compressor and hence the energy cost for the facility, (2) maximizing the user's preference for the air compressor location in the facility. The two goals are incorporated into a single objective function via a weighted sum of:

1) the product sum of i) distance between the air compressor location and each defined facility zone, ii) the compressed air demand (air volume * load factor), and iii) pressure at each respective zone. 
2) a predetermined parameter that defines the level of user preference for air compressor location, while incorporating zone availability with respect to zone temperature and existence using a binary constraint.

The resulting mathematical formulation of the proposed model can be written as follows:

$$
\hat{z} \underset{z \in\{1,2, \ldots, N\}}{\operatorname{argmin}}\left(\left[\alpha I_{z}+1\right] \times \sum_{i=1}^{N} \sum_{j=1}^{R_{i}}\left[\left(P_{i j} * \dot{V}_{i j} * l_{i j}\right) * D_{i z}\right]\right)+B_{z}
$$

Subject to:

$$
\begin{aligned}
& B_{z}=\left\{\begin{array}{lr}
0 & \text { when zone is feasible } \\
\infty & \text { otherwise }
\end{array}\right. \\
& 175 \mathrm{cfm} \leq \dot{V}_{i j} \leq 250 \mathrm{cfm} \\
& 0 \leq D_{i z} \leq d \\
& 0 \leq P_{i j} \leq 125 \text { psi } \\
& z \in\{1,2, \ldots, N\} \\
& 0 \leq l_{i j} \leq 1
\end{aligned}
$$

where:

$$
\begin{aligned}
& E=\sum_{i=1}^{N} \sum_{j=1}^{R_{i}}\left[\left(P_{i j} * \dot{V}_{i j} * l_{i j}\right) * D_{i z}\right] \\
& W=\alpha E \\
& D_{i z}=\left|X_{i}-X_{z}\right|+\left|Y_{i}-Y_{z}\right| \\
& I_{z}=1,2,3,4,5 \\
& 0 \leq \alpha \leq 1
\end{aligned}
$$

where $N$ and $R_{i}$ represents the number of zones in the facility and the number of machines in each zone respectively. Argmin is the value of $\mathrm{z}$ for which the objective function attains the $z \in\{1, N\}$

minimum output. For machine $j$ in zone $i, P_{i j}$ is the pressure (psig) requirement, $V_{i j}$ is the volume 
(cfm) requirement, and $l_{i j}$ is the load factor $(\%) . D_{i z}$ is the distance between zone $i$, and the potential air compressor zone $z$. The user preference for air compressor location of zone $z$ is represented by a multi-level user preference index, $I_{z}$, which is captured by the weight, $W$, in the objective function. $W$ is a linear function of the energy consumption term $E . \alpha \in[0,1]$ designates the fraction of $E$ used as $W$. When $\alpha=0$ the model will only minimize the energy consumption of the air compressor. When $\alpha=1$ the model will minimize both energy consumption and user preference equally. Clearly higher values of $W$ indicate cases where the user preference for air compressor location is more important to the user than energy efficiency. A higher $W$ normally leads to greater air compressor energy consumption within a given facility (See Section 3.2). Additionally, the feasibility of the air compressor location at zone $z$ is represented by a binary constraint, $B_{z}$, which considers zone temperature, zone existence, and zone feasibility. $d$ is the maximum possible rectilinear distance within the modeled facility. The optimal zone for air compressor location is the zone $z$ that minimizes the above function (1).

Figure 3 below illustrates the modeled problem.

Fig.3. Air Compressor Set-up and Relationship of Variables in Optimization Model

The air compressor positioned at zone $z$ feeds air to machine $J 1 \& J 2$ in zone $i$. As seen, $D_{i z}$ is the rectilinear distance from zone $z$ to zone $i, I_{z}$ is the user preference level at zone $z$, and $B_{z}$ is the binary constraint at zone $z$.

The following sections detail the various terms in the mathematical model.

\subsubsection{Distance Term in the Mathematical Model}

Minimizing distance $\left(D_{i z}\right)$ from the air compressor location $(z)$ to each air demand location (i) is one of the most significant determinants in minimizing air compressor energy consumption.

In order to understand the distance term $\left(D_{i z}\right)$ in the function, it is important to first describe how the model addresses the facility to be optimized. Facility size is given as an input of length and width in feet. The facility is then divided into zones for further analysis. Zone size selection will be discussed in section 2.3 of this paper. 
A rectilinear zone-to-zone distance matrix is established to determine the distance compressed air must travel to each demand zone $i$. The rectilinear distance between zones is used because it is the most representative of a compressed air piping distribution layout. For facilities that are not rectangular in shape, zones that do not fall within the established rectangular shape can be eliminated from analysis by using a binary constraint $\left(B_{z}\right)$ which will be discussed later in this section. Rectilinear distance between each zone is calculated using Equation (5) [36, 37].

$$
D_{i z}=\left|X_{i}-X_{z}\right|+\left|Y_{i}-Y_{z}\right|
$$

By minimizing distance to air demand locations, the compressed air system will experience a reduction in pressure drops and air leaks. Both pressure drop and air leaks have a significant effect on energy consumption in a compressed air system.

Pressure drop is linearly correlated to distance and can be expressed in equation (6) below:

$$
d p=\frac{7.57 * q^{1.85} * L * 10^{4}}{d^{5} * p}
$$

where $d p$ is the pressure drop in the pipe (psi), $\mathrm{q}$ is the volume flow rate $(\mathrm{m} 3 / \mathrm{min}), \mathrm{L}$ is the length of the pipe $(\mathrm{m}), \mathrm{d}$ is the diameter of the pipe $(\mathrm{mm})$, and $\mathrm{p}$ is the pressure in the pipe $(\mathrm{kg} / \mathrm{cm} 2)$. If all variables in equation 6 are kept constant and the length of the pipe is increased, it can be noticed that the pressure drop $d p$ in the pipe will increase linearly.

Air leaks are the second significant loss in compressed air systems. It is suggested in many areas that on average, compressed air systems lose up to $40 \%$ of the air produced to air leaks and are the single greatest loss of energy in compressed air systems at manufacturing facilities [29]. In general air leaks, occur at the joints, flange connections, elbows, reducing bushes, sudden expansions, valve systems, filters, hoses, check valves, relief valves, extensions, and the equipment connected to the compressed-air lines [29]. In this paper we focus mainly on the air leaks occurring at the joints of pipes. Since the number of machines in the modeled facility does not change, the assumption is made that hoses, check valves, equipment connected to compressed-air lines, etc. remain the same. The only significant variable that changes is the length of piping required to supply compressed air to air demand areas. The further the distance the more piping is required, which in turn means the more joints and the higher chance of leaks. 
The number of leaks is conservatively estimated at $1 / 64$ inch leak per $100 \mathrm{ft}$ of piping. The assumption is made that air leaks in the system are linearly proportional to distance.

Therefore it is suggested that reducing the distance compressed air must travel to high demand and high-pressure zones will result in a more efficient compressed air system with fewer pressure and leak losses.

\subsubsection{Energy Consumption Term of the Mathematical Model}

The energy consumption component of the proposed optimization model is derived in part by calculating effective demand and pressure requirements of the machines within the system. Effective air demand is the product of Volume $\left(V_{i j}\right)$, and Load Factor $\left(l_{i j}\right)$ of a machine [33]. Effective demand is used in industry to establish flow demand for compressed air systems [33, 38]. The objective function establishes a demand profile for the entire facility using the effective demand at each zone. The function positions the air compressor closest to the zones with the highest effective demand rate.

The load factor $\left(l_{i j}\right)$ of the machines at each zone are in part determined by data from Ingersoll Rand (See Table 1) [49]. The percent load of a machine in the facility determines the length of time the machine is on, and directly affects demand (cfm) in the facility. Obviously higher machine loads will result in higher compressed air demand making them both directly correlated.

The load of each machine in a facility can be very dynamic and is dependent on various factors such as production schedules, product demand, availability of raw materials, etc. Although Ingersoll Rand suggests loads for various types of machines, there can still be some unexpected load change or uncertainty that can affect air demand in a facility. In order to accurately model the load of each machine and to account for uncertainty in the facility, the model varies the load factor of each machine, using the suggested loads provided by Ingersoll Rand as guidance. This will be discussed further in sections 2.4 and 3.3 of the paper.

Air pressure $\left(P_{i j}\right)$ is the second significant determinant of air compressor energy consumption. Air pressure is linearly correlated to energy consumption; the higher the air compressor pressure set point or machine pressure requirement, the more energy required. In fact, for every 2 psi increase in the air pressure set point, the air compressor experiences a $1 \%$ 
increase in energy consumption $[31,33,39]$. In order to ensure that machines run uninterrupted, the air compressor must match the pressure requirements of each machine in the facility.

The proposed energy consumption term in the optimization model is:

$$
P_{W a t t s}=P_{i j} * \dot{V}_{i j} * L_{i j}
$$

To develop this term it is important to first derive power $\left(P_{\text {watts }}\right)$. To move compressed air from point $A$ to point $B$ work $(W)$ must be performed. To move an object, the linear path integral of the force component must be taken in the direction of motion, multiplied by the distance moved as shown in equation 8 .

$$
W=\int_{A}^{B} \vec{F} * \overrightarrow{d s}
$$

where $W$ is work, $F$ is force, and $d$ is distance.

We then replace $\vec{F}$ in equation 8 with the force per unit charge in an electric field $(E)$.

$$
\vec{E}=\frac{\vec{F}}{Q}
$$

where $E$ is the resulting electric field, and $Q$ is the unit charge.

Combining Equation 8 and 9 gives us the expression of work in an electric field to move a charge Q from point A to point B (10):

$$
W=\int_{A}^{B} \vec{E} * Q * d \vec{s}
$$

From equation 10 we can develop the expression of Power to move $Q$ in the electric field from one point to the next.

$$
\text { Power }=\frac{d W}{d t}=\int_{A}^{B} \frac{d Q}{d t} * \vec{E} * d \vec{s}=i * \int_{A}^{B} \vec{E} * d \vec{s}
$$

where $i$ is current and $i=d Q / d t$. The linear integral displayed in equation 11 is the Voltage term $(V)$.

$$
V=\int_{A}^{B} \vec{E} * d \vec{s}
$$


By substituting voltage into 12 we get the expression for instantaneous power.

$$
\text { Power }=V * i
$$

Through some dimensional analysis the expression of Power is then converted into watts as shown in equation 14.

$$
\text { Power }=\left[\frac{\left(\frac{\frac{K g * m^{2}}{s^{2}}}{s}\right)}{C}\right] *\left[\frac{C}{s}\right]=\frac{\frac{k g * m^{2}}{s^{2}}}{s}=\frac{N * m}{s}=\text { Watt }
$$

where $\mathrm{C}$ is coulombs, $\mathrm{N}$ is Newton's and is $\mathrm{N}=k g * m / s^{\wedge} 2 . m$ is meters and $s$ is seconds. Lastly $P_{\text {Watts }}$ is expanded to result in the Pressure $\left(P_{i j}\right)$ times Volume $\left(\dot{V}_{i j}\right)$ function in the optimization model.

$$
\begin{gathered}
P_{\text {Watts }}=\frac{N * m}{s}=\left[\frac{N}{m^{2}}\right] *\left[\frac{m^{3}}{s}\right] \\
P_{\text {Watts }}=P_{i j} * \dot{V}_{i j}
\end{gathered}
$$

\subsubsection{User Preference Index and Binary Constraint Terms in the Mathematical Model}

Although the most energy efficient location results in the least cost to the facility, our goal in the mathematical model is to also maximize the user satisfaction. By incorporating user preference, the user can identify preferred areas for air compressor location. The introduced user preference index and its associated weight add an additional degree of freedom to effectively manage the trade-off between the energy cost and the user's location preference.

To model the user's preference for air compressor location in the facility, a five level user preference index $I_{z}$ combined with a binary constraint $B_{z}$ is introduced (See Equation 1). The model uses an a priori preference [40] approach to represent the preference level of $I_{z}$ at each zone.

The user preference index has a range from 1 to 5 where 1 is the most desired (least inconvenient) location and 5 is the least desired (most inconvenient) location for the user. For example, zones that fall next to production lines or office space will normally be expected to have a preference index value of 5 (meaning most inconvenient), while zones that fall directly on 
the outside of the facility wall, or in an available space in the facility, will be assigned a preference index value closer to 1 .

The binary constraint $B_{z}$ is introduced to determine zone feasibility in the objective function. For this model, the proposed function assigns 0 to $B_{z}$ if a zone that exists within the true facility layout is feasible, and has a temperature that always falls within the defined temperature range $15^{\circ} \mathrm{F} \leq \mathrm{Tz} \leq 125^{\circ} \mathrm{F}$ [41], or $\infty$ otherwise. If the compressor is located inside the facility, but has an outside air intake, the outside temperature of the location is used. If the maximum or minimum outside air temperature (OAT) of the facility location does not fall within the prescribed temperature range for effective air compressor performance, the model will neither assign the compressor to an outdoor zone nor any prospective zone using an outside air intake. $B_{z}$ also indicates if a zone is feasible or not. Once a facility is initially defined as a rectangular shape, if the facility is actually an "L" shaped facility, the zones located outside the "L" shape will be designated as non-applicable zones by the function. Additionally, if a zone falls on a production line it is considered infeasible for air compressor location.

\subsection{Assumptions in Mathematical Model}

In this section the assumptions used in the optimization-simulation model are discussed. Some assumptions are mentioned and discussed further in their respective sections. This is done to give more background to the assumption.

It is assumed that the compressed air flow in the pipe will only be laminar and not turbulent. This assumption is made since the model is only designed for one compressor in one location

and therefore there should not be any friction causing turbulence in the pipes. Furthermore the model considers a well-designed piping system that minimizes $\mathrm{T}$-joints and dead ends hence reducing the turbulence in the piping structure significantly.

It is also assumed that for every 2 psi increase in the air pressure set point, the air compressor experiences a $1 \%$ increase in energy consumption [31, 33, 39]. This is discussed further in section 2.1.1. Since the number of demand locations and number of machines do not change in the model, piping drops are assumed to be uniform for each compressor location and do not affect the pressure drop analysis. 
The assumption is made that relevant air leaks only occur at joints in piping and occur at a rate of 1/64 inch leak per 100ft of piping. Hence the assumption that air leaks in the system is linearly proportional to distance. This is discussed further in section 2.1.1.

Lastly we assume that the compressed air system is set-up in the same way at each selected zone. Therefore the performance of the air compressor and the cost of the set-up are not affected the selected zone.

\subsection{Zone Size and Characteristics}

For the purpose of this research, a zone size is defined as a $20 \mathrm{ft}$ x $20 \mathrm{ft}$ square. This zone size was selected based on three considerations: 1) The selected zone size must be representative of an air compressor room size at a typical manufacturing facility in the United States, 2) the selected zone size must be representative of a typical area of air demand (machine area size) in a manufacturing facility, and 3) the selected zone size must not be too small as this will lead to unnecessary complications in the optimization process, making it inefficient and sometimes not feasible. On the other hand, if a zone size is too large, it will not be representative of the air compressor demand and pressure attributes for all parts of the zone area.

\subsubsection{Compressor Room Size and Layout}

It is recommended by OSHA that there be $4 \mathrm{ft}$ of space around each piece of electrical equipment in the compressor room for maintenance purposes and accessibility. The exact layout of the compressed air system will depend on several elements such as air quality, air supply, storage requirements, etc. Figure 4 below shows the typical setup in an air compressor room. Compressor Rooms typically consist of the following equipment: Air Compressor, Wet Storage Receiver, Air Dryer, Dry Storage Receiver, and filtration equipment [33].

As it can be seen in Fig. 4, there is $4 \mathrm{ft}$ of distance between each piece of equipment, and each piece of equipment and the walls of the room. Following this criterion illustrates that the zone size of $20 \mathrm{ft}$ x $20 \mathrm{ft}$ is representative of a compressor room in a manufacturing facility. For the purpose of this research the equipment is set-up in a square footprint, however this equipment can be set-up whichever way the facility chooses to as long as it meets the OSHA suggested 4ft spacing.

Fig.4. Typical Air Compressor Room Set-up and Foot Print 


\subsubsection{Typical Area of Air Demand (Machine Sizes)}

Typical area of zone $i$ for air demand also plays an important role in the selection of zone size. According to the "Facilities Design" book by Sunderesh S. Heragu we see that the average foot print of a machine in a production area typical facility is $346 \mathrm{sq} / \mathrm{ft}$ [42]. This is a bit less than the $400 \mathrm{sq} / \mathrm{ft}$ per zone size suggested in this paper.

\subsubsection{Zone Size Representation}

Finally we test the selected zone size to ensure that the placement of the air compressor at any part of the zone will have negligible pressure drop and air leaks from one point to the next. Using Pythagoreans Theorem we calculate the longest point air must travel from one corner of the zone to the next as $28 \mathrm{ft}$. Based on the air leak assumption stated above, air leaks on the joints of pipes can be assumed negligible. Furthermore the calculated pressure drop using equation 6 above is $0.054 \mathrm{psi}$, which can also be considered negligible.

Once the facility is divided into zones, additional zones are assigned to the outer perimeter of the facility. This allows for the optimization model to consider assigning the air compressor to an area directly outside of the facility wall (See Fig 9). Positioning compressors on the outside of facilities is a common practice in warmer environments where freezing temperature is not an issue.

The Load Factor $\left(l_{i j}\right)$ and Volume $\left(V_{i j}\right)$ is calculated for each individual machine at each respective zone. To account for the uncertainty of demand in the facility the model randomly shifts the load factor of each machine within a prescribed range. In this paper, air pressure $\left(P_{i j}\right)$ requirement is calculated as the maximum pressure required at each zone. For example, if the user defines two machines for Zone 1 and machine 1 has a minimum pressure requirement of 90 psi, and machine 2 has a minimum pressure requirement of 110 psi then the pressure requirement for the respective zone will be 110 psi.

\subsection{Simulation-Optimization Methodology for Identifying Optimal Location}

In this paper, a simulation-optimization technique is used to identify the optimal location that satisfies the optimization model and its constraints. Simulation-optimization provides the 
capability to determine the optimal zones in the facility by evaluating all possible facility designs and determining the optimal solution for the specific set of constraints and parameters [43-46]. Simulation-optimization is used because it can effectively find the optimal or near optimal solution with uncertainties present. The proposed model has uncertainty in the machine load factor. This is done to account for variations in compressed air demand and is discussed further in section 3.3. 1,500 iterations of the facility were simulated to test the effect of the load variation on the optimal air compressor location. The model also conducts a sensitivity analysis on all possible weights of the user preference, which can be done directly using the simulationoptimization technique.

Moreover in simulation-optimization the change in complexity of the system does not significantly affect the performance of the model, and the objective function and constraints can be changed from one run to the next for all alternative designs in the system [47]. It also used since it offers a more visual and comprehensive approach to finding the optimal solution. This allows for the model to be generalized further and be used by practitioners with limited knowledge of the mathematical formulations embedded in the model. All of this allows for increased complexity and flexibility in future model designs.

The proposed model evaluates all iterations of the facility before finding the optimal solution. By defining a finite number of zones and defining their boundaries and characteristics, the performance output for all zones in the facility model is calculated for each iteration. Minimizing the performance output will result in the optimal location with high probability that satisfies the objective function. Figure 5 illustrates a graphical representation of the proposed simulationoptimization approach. As it can be seen, the model will move from zone to zone calculating a performance output for each location of the air compressor. All zones of the facility are evaluated.

Fig.5. Graphical Representation of Simulation-Optimization Approach.

For the modeled facility the proposed simulation model will run $n$ number of times, where $n$ is the number of total zones in the facility. This will calculate the compressor capacity needed to supply air demand at all zones in the facility. This is mathematically represented in equation 17 below. 


$$
\begin{aligned}
& \hat{z}=\min {\left[\left(\left[\alpha I_{1}+1\right] \times \sum_{i=1}^{N} \sum_{j=1}^{R_{1}}\left[\left(P_{i, j} * \dot{V}_{i, j} * l_{i, j}\right) * D_{i, 1}\right]\right)+B_{1}\right] } \\
&+B_{2}+\left\lceil\left(\left[\alpha I_{2}+1\right] \times \sum_{i=3}^{N} \sum_{j=1}^{R_{1}}\left[\left(P_{i, j} * \dot{V}_{i, j} * l_{i, j}\right) * D_{i, 2}\right]\right)+B_{2}\right]+\cdots\left\lceil\left(\left[\alpha I_{n}+1\right] \times \sum_{i=1}^{N} \sum_{j=1}^{R_{1}}\left[\left(P_{i, j} * \dot{V}_{i, j} * l_{i, j}\right) *\right.\right.\right. \\
&\left.\left.\left.D_{i, n}\right]\right)+B_{n}\right\rceil
\end{aligned}
$$

Once the parameters and attributes of each zone have been defined, a simulation-driven analysis is conducted for the proposed optimization model.

\section{Simulation Driven Analysis of the Proposed Optimization Model}

A simulation driven analysis is conducted to investigate the feasibility of using the proposed objective function for finding the optimal air compressor location in a facility. The experimental analysis is conducted in three phases: The facility model is first developed, zone characteristics are defined, and a simulation analysis is then conducted to find the optimal air compressor location.

\subsection{Phase 1: Facility Model Development}

The facility size and layout are defined and incorporated in the model, and the facility is divided into zones. Special attention is taken to generate a simulation environment that realistically represents the characteristics of a typical manufacturing facility in the United States. The facility model is developed based on the authors' experience visiting over seventy manufacturing facilities in the United States. A rectangular shaped facility layout is selected for this simulation analysis (See Fig. 6.).

The considered facility has a length of 260 feet and a width of 160 feet resulting in a 41,600 sq/ft area (Fig. 6.). The figure legend shows the seven main areas in the facility. These are: Outside Space (perimeter of facility wall), Office Space, Production Area, Machine Shop, Paint and Sandblasting Area, Shipping and Receiving, and Warehouse Space. As discussed in section 2.2.1, a square zone size of $20 \mathrm{ft}$ x $20 \mathrm{ft}$ was selected as it is representative of an ideal compressed air demand area in a facility. This zone size resulted in the facility being divided into 150 zones. 104 zones represent the inner facility area, while 46 zones represent the perimeter of the facility. Once the facility layout and zones are established, the characteristics of each zone are defined. 


\subsection{Phase 2: Zone Characteristics Identification}

For this facility model, fifty-nine machines were defined (Table. 1) at twenty-four zones in the facility (Fig. 6). Fig. 6 displays the demand zones for the established facility and the associated user preference for each zone in the facility. The user preference levels are assigned using preferential locations as suggested by twenty-two experienced facility managers. The value of $I_{z}$, varies across individual users. As it can be see, the facility is divided into $15020 \mathrm{ft}$ x $20 \mathrm{ft}$ zones. NA represents zones that are not feasible for air compressor location (Fig.6).

Fig. 6. Modeled Facility, Identified Demand Zones and User Preference per Zone

The air temperatures for all zones in the facility satisfy the temperature constraint in the objective function. This assumption is based on two important factors: 1) The facility location was set in Miami, Florida where the outside temperature always falls within the appropriate temperature range for air compressor operation [48], and 2) The outside air temperature will be used as the base temperature throughout the interior of the facility since it is assumed that the air compressor will have an outside air intake at any selected zone.

Machines are picked to correspond with appropriate areas in the facility. For example, the machine shop area has pneumatic tools (sanders, grinders, screwdrivers) that are usually found in a typical machine shop in a manufacturing facility. Furthermore, the air volume, pressure, and load factor of each tool is also representative of actual tool settings and usage (See Table 1) [49]. It is important to note that the model varies the load factors shown in Table 1 to account for the uncertainty of changing demand.

\section{Table 1}

Displays pressure (psi), load factor, and volume (cfm) for each individual machine, at each zone in the modeled facility.

Once the facility model is established, an air demand profile is generated for the facility (Fig.7). The air demand is dependent on the Volume $V_{i j}$ and Load Factor $l_{i j}$ of each machine present at each zone $i$. The resulting range in total facility $\mathrm{cfm}$ demand across all iterations was $203.8 \mathrm{cfm}$ to $225.2 \mathrm{cfm}$. A sample of the air demand profile in the facility is shown in Fig. 7. 
Fig. 7. Air Demand (cfm) at Twenty-Four Zones in Modeled Facility.

\subsection{Phase 3: Simulation Analysis}

A simulation-driven analysis is conducted to identify the optimal air compressor location for the modeled facility. The analysis is developed and implemented in MATLAB due to its effectiveness at solving simulations. Other software such as LabVIEW, and ARENA Simulation Software can also be used.

The simulation analysis is performed for the following set-ups of the model:

1) To find the most energy efficient air compressor location with no articulation of location preference by the user or consideration of zone feasibility (Energy Baseline).

2) To find the most optimal compressor location by conducting a sensitivity analysis on all weights $(\alpha \in[0,1])$ of user preference in the function and with consideration of zone feasibility.

1,500 iterations of the facility model are simulated. For each iteration, the model randomly varies the suggested load factor of each machine by $\pm 20 \%$. This allows for the model to accurately incorporate uncertainty of load variations in the facility. With $95.2 \%$ probability of correct selection, Zone 85 (Z85) is the optimal location with no articulation of user preference. Furthermore, Zone 83 (Z83) in $4.8 \%$ of the runs was identified as the alternative optimal location. An additional 500 iterations were run to assess the difference in savings of Z85 in comparison to Z83, which was found to be $0.065 \%$ on average. The range of savings at zone will be discussed later in this section.

Zone 85 is the optimal location with no articulation of user preference. Because the proposed model also considers user preference, the energy optimal location (Zone 85) is not always the best location for the air compressor. By incorporating user preference into the model, the identified optimal location can shift depending on the user preference level at each zone. In this case, Zone 85 is not feasible for an air compressor location since it falls on a production line. Considering user preference will result in a shift of the optimal location which is further discussed below.

To understand the relationship between user preference and energy consumption, the authors conduct a sensitivity analysis on the model by assigning different weights to the user preference in order to investigate the effect it has on the resulting solution. Several values of $\alpha$ from $0-1$ 
were tested. More specifically each simulated iteration of the facility was run 100 times for 0.01 intervals and the resulting output was noted. Figure 10, 11, and 12 show samples of three tested $\alpha$ outputs. The sensitivity analysis resulted in three distinct optimal zones with high probability. For a high energy priority, Zone 70 (Z70), with a probability of $97.3 \%$, is found optimal for $\alpha \in$ $[0,0.05]$. For a balance between energy and user preference, Zone 130 (Z130), with a probability of $96.7 \%$, is found optimal for $\alpha \in(0.05,0.13]$. For a high user preference priority Zone 145 (Z145), with a probability of $99.1 \%$, is found optimal for $\alpha \in(0.13,1]$. Fig. $8 \& 9$ display the locations of these zones in the facility (See Table 2).

Fig. 8. Facility Layout with Energy Efficient (Z85) and Identified Optimal Locations (Z70, Z130, and Z145)

A 3-D representation of the energy/performance output that is required by the air compressor to meet air demand at each zone in the facility is presented in Fig. 9. Since the model is set to minimize the utility function, the lowest calculated energy output results in the most energy efficient zone. It can also be seen that by increasing the weight of $\alpha$ in the model, the optimal zone shifts to a zone with a higher, more acceptable user preference index.

Fig. 9. 3-D Representation of Energy Output at Each Zone

Additionally Fig. 9 displays that the further away the air compressor from Z85, the larger the required energy/performance output.

Since the model shifts the load factor of each machine in the facility, the demand for compressed air will vary for each iteration. The resulting range in total facility cfm demand across all iterations was $203.8 \mathrm{cfm}$ to $225.2 \mathrm{cfm}$. This will in turn cause variation in the potential energy savings. The range of possible energy savings resulting by placing the air compressor at Zone 85 is $8.59 \%$ to $13.94 \%$ with an average energy savings of $10.97 \%$. Zone 70 , the optimal zone for $\alpha \in[0,0.05]$ has a possible energy savings range of $8.03 \%$ to $13.06 \%$ with an average savings of up to $10.31 \%$. Zone 130 , the optimal zone for $\alpha \in(0.05,0.13])$ resulted in a possible energy savings range of $6.27 \%$ to $11.38 \%$ with an average savings of up to $8.34 \%$ and finally, 
Zone 145 , the optimal zone for $\alpha \in(0.13,0.1])$ resulted in a possible energy savings range of $4.91 \%$ to $9.64 \%$ with an average savings of up to $6.28 \%$ (See Table 2).

Table 2 displays the results of the simulation-driven analysis.

\section{Table 2.}

Results of simulation-driven analysis. Table 2 displays the probability of correct selection of the optimal zones, the range of savings and average savings for all iterations of the model. Note that Zone 85 and 83 are optimal with no articulation of user preference.

As shown in section 3.3, as the user preference priority increases the potential energy savings will decrease. In fact there is a $4.62 \%$ reduction in potential savings between Z145 and Z85; however, Z145 can still potentially save an average of $6.2 \%$ even with the highest user preference priority.

Fig.10 illustrates the potential energy savings at each optimal zone for each iteration of the facility.

Fig. 10. Resulting Percent Savings for Each Model Iteration

As shown in Fig. 10, Zone 85 results in the highest potential savings. As the weight of user preference increases the optimal location shifts to Zone 70, Zone 130, and Zone 145 respectively. This shift reduces the potential energy savings achievable by the model while increasing the user's preference for location. Even with a high user preference the model can still achieve significant savings.

To understand the effect of the user's preference $\alpha$ on the optimization model, the energy baseline $(\alpha=0)$ is plotted against samples of the energy/performance output for $\alpha=0.05,0.12$, and 0.2. The selected values of $\alpha$ fall within the range of that identifies optimality with high probability at zone Z70, Z130, and Z145 respectively.

Fig. 11. Baseline Energy vs. Energy with User Preference $\alpha=0.05$.

As it can be seen in Fig. 11, a selected weight of $\alpha=0.05$ results in the model reaching optimality at Z70 (Fig. 11). Zones assigned NA (not feasible) are not considered in the analysis, 
hence the missing red bars in the chart. Z70 has a user preference level of 5 in the model indicating a zone with a low user preference index.

Next the model is run for $\alpha=0.12$ (Fig. 12). Running the model for $\alpha=0.12$, the optimal zone shifts from Z70 to Z130 (Fig. 12). The shift results in an optimal zone with a user preference level index of 2. This indicates that the zone is more favorable to the user. Z130 balances both the energy consumption and the user's preference.

Fig. 12. Baseline Energy vs. Energy with User Preference $\alpha=0.12$.

Last the model is run for $\alpha=0.2$ (Fig. 13). Plotting the effect of $\alpha=0.2$, results in the optimal zone shifting from Z130 to Z145 (Fig. 13). Z145 has a user preference index of 1.For this particular model, $\alpha \geq 0.13$ will always result in Z145 as the optimal zone. Z145 is on the outside perimeter of the facility, and is most favorable to the user and has a higher energy/performance output than Zone 85, 70, and 130.

Fig. 13. Baseline Energy vs. Energy with User Preference $\alpha=0.2$.

Running a sensitivity analysis shows effect of increasing $\alpha$, on the resulting optimal locations (Fig. 14). In this case, only feasible zones (Zones that have a user preference index from 1-5) are plotted in ascending order of energy/performance output.

Fig. 14. Energy Baseline vs. Energy with User Preference $\alpha=0.05,0.12$, and 0.2 .

As $\alpha$ increases, so does the air compressor performance output at the resulting optimal zone. The energy cost vs. user preference trade-off is clearly displayed by the resulting optimal zone shifting to the right as the weight $(\alpha E)$ of the user preference increases. 


\section{Validation of Optimization Model using Mathematical Theorems}

In order to validate the proposed simulation-optimization model, a novel analytical mathematical model using several standardized equations is established to compare the three derived optimal zones (Z70, Z130, and Z145) with five zones, including the most energy efficient zone (Z85), least energy efficient zone (Z1), and three other zones selected at random.

The first step is to calculate the air leaks (cfm) resulting from locating the air compressor in each of the eight selected zones. Air leaks contribute significantly to wasted energy in a compressed-air system, sometimes accounting for $20-50 \%$ of the compressor output [29]. The resulting air leaks can be calculated using equation (18) [1]:

$$
V_{f}=\frac{N L *\left(T_{i}+460\right) * \frac{P_{l}}{P_{i}} * C_{1} * C_{2} * C_{d} * \frac{\pi D^{2}}{4}}{C_{3} * \sqrt{T_{i}+460}}
$$

where $V f=$ volumetric flow rate of free air, cubic feet per minute, $T_{i}=$ temperature of the air at the compressor inlet (yearly average), $76.5^{\circ} \mathrm{F}, P_{l}=$ line pressure at leak in question, psia (100 psia), $P_{i}=$ inlet (atmospheric) pressure, psia, $C 1=$ isentropic sonic volumetric flow constant, $28.37 \mathrm{ft} / \mathrm{sec}^{-} \mathrm{R} 0.5, C 2=$ conversion constant, $60 \mathrm{sec} / \mathrm{min}, C d=$ coefficient of discharge for square edged orifice1, 0.8 no units, $\pi=$ Pythagorean constant, 3.1416, $C 3=$ conversion constant, 144 in $2 / \mathrm{ft} 2, T_{l}=$ average line temperature, $76.5^{\circ} \mathrm{F}$ (assumed to be the same as temp at the leak), $D=$ leak diameter is estimated as 1/64 inches for all identified leaks, and $N L=$ the number of leaks is conservatively set as 1/64 inch leak per $100 \mathrm{ft}$.

The distance from the selected compressed air zone to each demand zone is used in calculating the total number of leaks in the system (NL). Since the number of demand locations and number of machines do not change, piping drops are assumed to be uniform for each of the six selected zones.

Total pressure drop resulting from positioning the air compressor in the eight zones is then calculated. The further away the air compressor is from a demand zone the higher the resulting pressure drop. Pressure drop is calculated using equations 19 and 20 [1] below: 


$$
\begin{gathered}
f=\frac{0.1025 L Q^{2}}{r d^{5.31}} \\
r=\frac{\text { Pressure }(p s i)+\text { Atmospheric Pressure at Location }(p s i)}{\text { Atmospheric Pressure at Location }(p s i)}
\end{gathered}
$$

where $f=$ pressure drop (psi), $L=$ total length of pipe (ft) to demand zones, $Q=$ cubic feet of free air per second plus total air leaks per zone location calculated in the previous section, $r=$ ratio of compression (from free air) at entrance of pipe, $d=$ actual internal pipe diameter (Selected as 2 inches based on the total demand of the facility, and 0.0125 is the experimental coefficient for the selected pipe size [50].

Theoretical horsepower and the effective horsepower of the air compressor at each zone is calculated. Once the theoretical horsepower is calculated (Uses the cfm losses from Equation 18), the energy consumption increase due to pressure drop is applied resulting in the effective horsepower required to meet air demand in the facility. Equation (21) [51] below is used to calculate the theoretical horsepower:

$$
H P=\left[\frac{144 * N * P_{1} * V * k}{33,000 *(k-1)}\right] *\left[\left(\frac{P_{2}}{P_{1}}\right)^{\frac{(k-1)}{N * k}}-1\right]
$$

where $H P=$ horsepower, $N=$ number of compression stages which in this case is set to $1, k=$ 1.41 = adiabatic expansion coefficient, $P_{l}=$ absolute initial atmospheric pressure (psi) (14.7 psi at sea level), $P 2$ = absolute final pressure after compression (psi) in this case $100 \mathrm{psi}, V=$ volume of air at atmospheric pressure (cfm) calculated as total demand for the air compressor location and the total demand resulting from the air leaks.

\subsection{Results of Validation}

The effect of the air compressor location on energy consumption is displayed by the resulting energy consumption $(\mathrm{kW})$ required to meet demand at each of the eight selected locations (See Table 3).

An energy savings of up to $2.98 \mathrm{~kW}$ or $10.8 \%$ can be achieved by placing the air compressor in the most energy efficient location Z85. Z70, Z130, and Z145 can save up to $10.11 \%, 8.1 \%$, and $6.2 \%$ in energy consumption respectively. As expected, there is an increase in air 
compressor energy consumption as the weight of the user's preference increases in the objective function. The increase in energy consumption between Z85 (Energy Baseline) and Z70, Z130, and $\mathrm{Z} 145$ is $0.69 \%, 2.7 \%$, and $4.6 \%$ respectively.

\section{Table 3.}

Summary of Validation Results for the Eight Selected Zones. Table 3 displays the resulting air leaks, pressure drop (psi and \%), horsepower (theoretical and effective), and energy consumption $(\mathrm{kW})$ at each zone. Horsepower (hp) is converted to kilowatt $(\mathrm{kW})$ using the conversion ratio of 1hp to $0.746 \mathrm{~kW}$.

These results suggest that a significant energy and cost savings can be attained by optimizing the air compressor location using the proposed objective function (1). The results also suggest that incorporating user preference can also lead to significant energy savings while maintaining a desired air compressor location. There is a noticeable trade-off between energy consumption and user preference. As the user's preference weight $\alpha$ increases in the function, so does the energy consumption of the newly identified optimal zone.

As the air demand at the facility increases, so will the potential $\mathrm{kW}$ and percent savings. It is also important to understand that in order to sustain energy savings in a compressed air system, there must be a continuous improvement application as further discussed in ISO50001 [26].

\section{Conclusion}

In this paper a simulation-optimization model is proposed to determine the optimal air compressor location in a facility. The developed model minimizes the total energy consumption of the air compressor while concurrently considers the user's preference for air compressor location. A simulation driven analysis is conducted in order to identify the optimal air compressor location. Additionally a sensitivity analysis is performed by assigning different levels of weight to user preference in order to investigate effect of the user's preference $\alpha$ on the optimization model.

The results reveal a significant reduction in energy consumption. It is important to note that the model identified Zone 85 as the energy optimal location with $95.2 \%$ probability of correct selection. Placing the air compressor in the most energy efficient location (Z85) results in an energy savings of $8.59 \%$ to $13.94 \%$ with an average energy savings of $10.97 \%$. Energy savings when the model considers user preference are less but still significant with Zone 70 saving 
$8.03 \%$ to $13.06 \%$ with an average savings of $10.31 \%$. Zone 130 resulted in possible energy savings range of $6.27 \%$ to $11.38 \%$ with an average savings of $8.34 \%$ and finally Zone 145 resulted in possible energy savings range of $4.91 \%$ to $9.64 \%$ with an average savings of $6.28 \%$. There is a $4.62 \%$ loss in energy efficiency as the air compressor location shifts from Zone 85 (most energy efficient) to Zone 145 (maximum user preference priority). Nonetheless Zone 145 is still able to save an average of $6.2 \%$ in energy usage.

To investigate and demonstrate the effectiveness of the simulation-driven analysis, a novel mathematical formulation using several standardized equations is used to compare the derived optimal zones (Z70, Z130, and Z145), with five other zones, including but not limited to the most energy efficient (Z85) and least energy efficient (Z1) zones.

The effect of the air compressor location is demonstrated by the impact that the eight selected locations have on the total $\mathrm{kW}$ required to meet compressed air demand in the facility. An energy savings of up to $2.98 \mathrm{~kW}$ or $10.8 \%$ can be achieved by placing the air compressor in the most energy efficient location Z85. Z70, Z130, and Z145 can save up to $10.11 \%, 8.1 \%$, and $6.2 \%$ in energy consumption respectively. As expected, there is an increase in air compressor energy consumption as the weight of the user's preference increases in the objective function. The increase in energy consumption between Z85 (Energy Baseline) and Z70, Z130, and Z145 is $0.69 \%, 2.7 \%$, and $4.6 \%$ respectively.

These results suggest that by using the proposed model to optimize the air compressor location in a facility, significant energy reductions can be achieved while maintaining the user's desired air compressor location. The results also suggest that as the weight of the user preference variable goes up, so will the associated energy of the resulting optimal zone.

Since the proposed objective function is tailored towards maximizing the energy efficiency of an air compressor system, its benefits are best realized when the model can effectively capture and integrate the user preference index in its analysis. Such a component will be more effective deducing the user's preference via a prediction preference model. An applicable extension to this research would be to develop an effective and practical mechanism to accomplish this task. It must also be noted that the proposed objective function is for a single air compressor setup in a facility. Further studies can be conducted to incorporate systems with multiple air compressors at multiple zones and variation in temperature at each zone into the model. 
Compressed air systems account for $23 \%$ of total mechanical drive electric consumption in manufacturing facilities and are only $11 \%$ efficient. Having said that they are one of the least understood systems. In this research, the authors show that optimizing the location of air compressors in manufacturing facilities can reduce energy costs while considering the users preference for location. This is an important step to creating an optimal compressed air system.

\section{Acknowledgement}

This research has been partially funded by a grant from the U.S. Department of Energy for the University of Miami Industrial Assessment Center.

\section{References}

[1] C. Air, J.P. Rollins, Compressed air and gas handbook, Compressed Air and Gas Institute, 1961.

[2] R.S. Foss, Optimizing the compressed air system, (2005).

[3] U.S.D.o. Energy, Advanced Manufacturing Office: Compressed Air Market Assessment, 2014 (2014).

[4] I. XENERGY, Compressed Air Efficiency Services, in, U.S Department of Energy, Office of Industrial Technologies, Office of Energy Efficiency and Renewable Energy, 2001.

[5] Y. Cerci, Y.A. Cengel, R.H. Turner, Reducing the cost of compressed air in industrial facilities, in: International Mechanical Engineering Congress and Exposition, 1995, pp. 12-17.

[6] L.B.N. Laboratory, Working Within Markets to Affect Change, in, Environmental Energy Technologies Division, EETD Newsletter, 1999.

[7] A.P. Senniappan, Baselining a compressed air system-an expert systems approach, in, West Virginia University, 2004.

[8] E.M. Talbott, Compressed air systems: a guidebook on energy and cost savings, The Fairmont Press, Inc., 1993.

[9] I. XENERGY, United States Industrial Electric Motor Systems Market Opportunities Assessment, Washington, DC: Office of Energy Efficiency and Renewable Energy, Office of Industrial Technologies, (2002) 386.

[10] C.A. Institute, Gas, Working With Compressed Air, 2014 (2012). 
[11] C. Yuan, T. Zhang, A. Rangarajan, D. Dornfeld, B. Ziemba, R. Whitbeck, A decision-based analysis of compressed air usage patterns in automotive manufacturing, (2006).

[12] U.S.E.I. Administration, MANUFACTURING ENERGY CONSUMPTION SURVEY (MECS), in, 2010.

[13] U.S.D.o.E. -Energetics, Manufacturing Energy and Carbon Footprint, in, Advanced manufacturing Office, 2010.

[14] J.D. Risi, Energy savings with compressed air, Energy engineering, 92 (1995) 49-58.

[15] J. Holdsworth, Conserving energy in compressed air systems, Plant Engineering (Chicago), 51 (1997).

[16] M.A. Koski, Compressed Air Energy Audit “The Real Story”, Energy engineering, 99 (2002) 59-70.

[17] I.R.A.S. Group, Compressed Air Systems Energy Reduction Basics, in, 2001.

[18] R. Sweeney, Cutting the cost of compressed air, Machine design, 74 (2002) 76-78.

[19] C.A. Challenge, Fundamentals of Compressed Air Systems, (2014).

[20] S.B. Cengel YA, Tuner RH, Cerci Y, Reduced compressed air costs, Hydrocarbon Processing, 2000.

[21] I.F.d. Chunha, Compressed air energy efficiency reference guide book, CEA Technologies, Canada, 2007.

[22] D. Kaya, P. Phelan, D. Chau, H. Ibrahim Sarac, Energy conservation in compressed-air systems, International journal of energy research, 26 (2002) 837-849.

[23] UD-IAC, University of Dayton Industrial Assessment Center, in, UD-IAC, 2009.

[24] E. Efficiency, R. Energy, Improving Compressed Air System Performance.

[25] M.J. McKane A, Aylwin R, Bertoldi P, Cockburn J, Cockrill C., Creating an International Standard for Motor Software, Energy Efficiency in

Motor Drives, in: EEMODS, 2005.

[26] I. 50001, International Organization for Standardization, in, International Organization for Standardization, 2011.

[27] M. Akbaba, Energy conservation by using energy efficient electric motors, Applied Energy, 64 (1999) 149-158.

[28] B.L. Capehart, W.C. Turner, W.J. Kennedy, Guide to energy management, The Fairmont Press, Inc., 2006. 
[29] R. Saidur, N. Rahim, M. Hasanuzzaman, A review on compressed-air energy use and energy savings, Renewable and Sustainable Energy Reviews, 14 (2010) 1135-1153.

[30] A. McKane, Improving energy efficiency of compressed air system based on system audit, Lawrence Berkeley National Laboratory, (2008).

[31] M. D’Antonio, G. Epstein, S. Moray, C. Schmidt, Compressed air load reduction approaches and innovations, in: Proceedings of the twenty-seventh industrial energy technology conference, New Orleans, 2005.

[32] C.A.C.-U.S.D.o. Energy, Pressure Drop and Controlling System Pressure, in: Improving Compressed Air System Performance - A Sourcebook for Industry, Compressed Air Challenge U.S. Department of Energy, Compressed Air Challenge, 1998.

[33] K. Compressors, Designing Your Compressed Air System, in: K. Compressors (Ed.) How to Determine the System You Need, Kaeser Compressors, Compressed Air System Guide, 2000. [34] C.A.a.G. Institute, Air Compressor Selection and Application, in, Compressed Air and Gas Institute, http://www.cagi.org/, 2002.

[35] Q. Compressors, How to Size and Select an Air Compressor, in.

[36] L.G. Chalmet, R.L. Francis, A. Kolen, Finding efficient solutions for rectilinear distance location problems efficiently, European Journal of Operational Research, 6 (1981) 117-124. [37] M. Hanan, On Steiner's problem with rectilinear distance, SIAM Journal on Applied Mathematics, 14 (1966) 255-265.

[38] R.N. Brown, Compressors: Selection and sizing, Gulf Professional Publishing, 1997.

[39] G. Christina, E. Worrell, Energy efficiency improvement and cost saving opportunities for the vehicle assembly industry, in, LBNL-50939-Revision, 2008.

[40] P. Ngatchou, A. Zarei, M. El-Sharkawi, Pareto multi objective optimization, in: Intelligent Systems Application to Power Systems, 2005. Proceedings of the 13th International Conference on, IEEE, 2005, pp. 84-91.

[41] I.-R. Company, Installation, Operation and Maintenance Instructions

for Models, in, 2005.

[42] S.S. Heragu, Facilities design, iUniverse, 2006.

[43] J.R. Swisher, S.H. Jacobson, E. Yücesan, Discrete-event simulation optimization using ranking, selection, and multiple comparison procedures: A survey, ACM Transactions on Modeling and Computer Simulation (TOMACS), 13 (2003) 134-154. 
[44] J. April, F. Glover, J.P. Kelly, M. Laguna, Practical introduction to simulation optimization, in: Simulation Conference, 2003. Proceedings of the 2003 Winter, IEEE, 2003, pp. 71-78.

[45] J.R. Swisher, P.D. Hyden, S.H. Jacobson, L.W. Schruben, A survey of recent advances in discrete input parameter discrete-event simulation optimization, IIE Transactions, 36 (2004) 591600.

[46] J.R. Swisher, P.D. Hyden, S.H. Jacobson, L.W. Schruben, A survey of simulation optimization techniques and procedures, in: Simulation Conference, 2000. Proceedings. Winter, IEEE, 2000, pp. 119-128.

[47] F. Azadivar, Simulation optimization methodologies, in: Proceedings of the 31st conference on Winter simulation: Simulation---a bridge to the future-Volume 1, ACM, 1999, pp. 93-100.

[48] T.W. Channel, Monthly Weather Forecast for Miami, FL, 2014 (2014).

[49] I. Rand, Air Consumption Chart for Industrial Type Tools, in, Ingersoll Rand, Industrial Air Power, 2013.

[50] M.L. Nayyar, R.C. King, S. Crocker, Piping handbook, McGraw-Hill New York, 2000.

[51] T.E. ToolBox, Horsepower required to Compress Air, 2014 (2014).

\section{List of Figures}

Fig 1. Cost of Energy Delivery Modes [11]

Fig.2. Energy Savings Opportunities in Air Compressor Systems [25]

Fig.3. Air compressor set-up and relationship of variables

Fig.4. Typical Air compressor room set-up and foot print

Fig.5. Graphical representation of simulation-optimization approach.

Fig. 6. Modeled Facility, Identified Demand Zones and User Preference per Zone

Fig. 7. Air Demand (cfm) at Twenty-Four Zones in Modeled Facility.

Fig. 8. Facility Layout with Energy Efficient (Z85) and Identified Optimal Locations (Z70, Z130, and Z145)

Fig. 9. 3-D Representation of Energy Output at Each Zone

Fig. 10. Resulting Percent Savings Potential by each Model Iteration

Fig. 11. Baseline Energy vs. Energy with User Preference $\alpha=0.05$.

Fig. 12. Baseline Energy vs. Energy with User Preference $\alpha=0.12$. 
Fig. 13. Baseline Energy vs. Energy with User Preference $\alpha=0.2$.

Fig. 14. Energy Baseline vs. Energy with User Preference $\alpha=0.05,0.12$, and 0.2. 


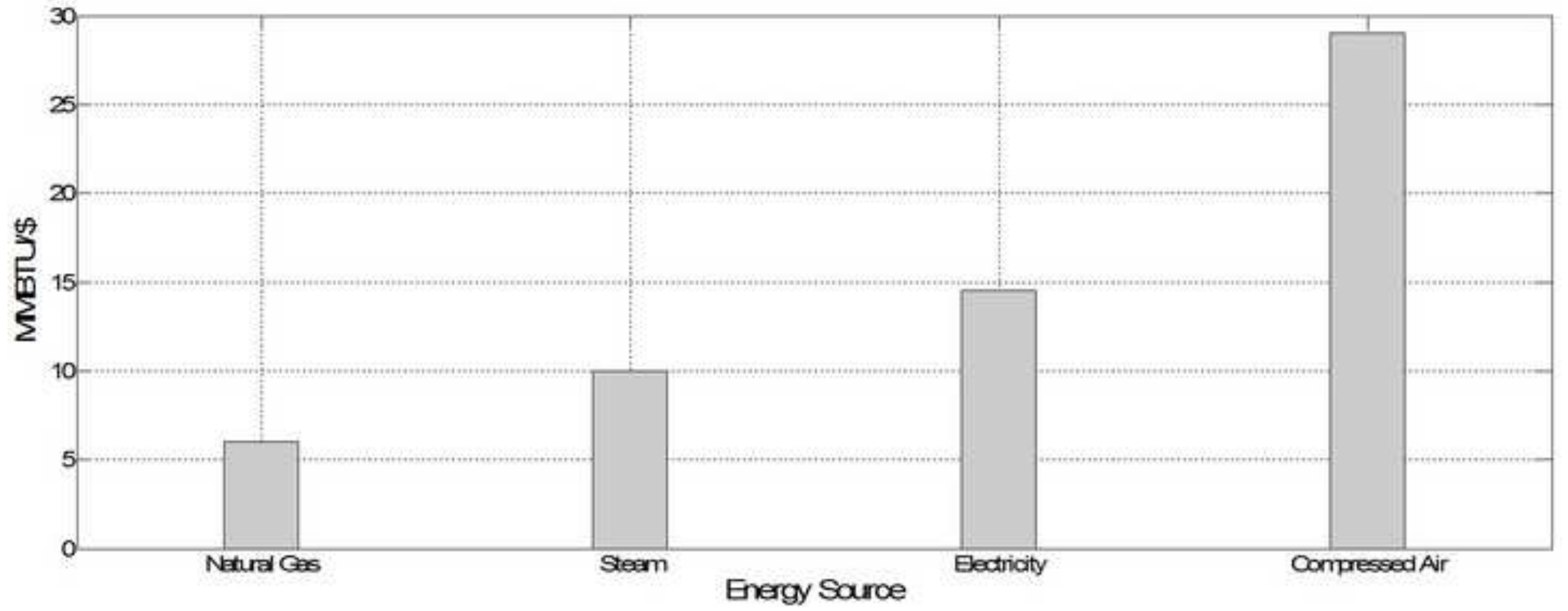

Page 33 of 49 


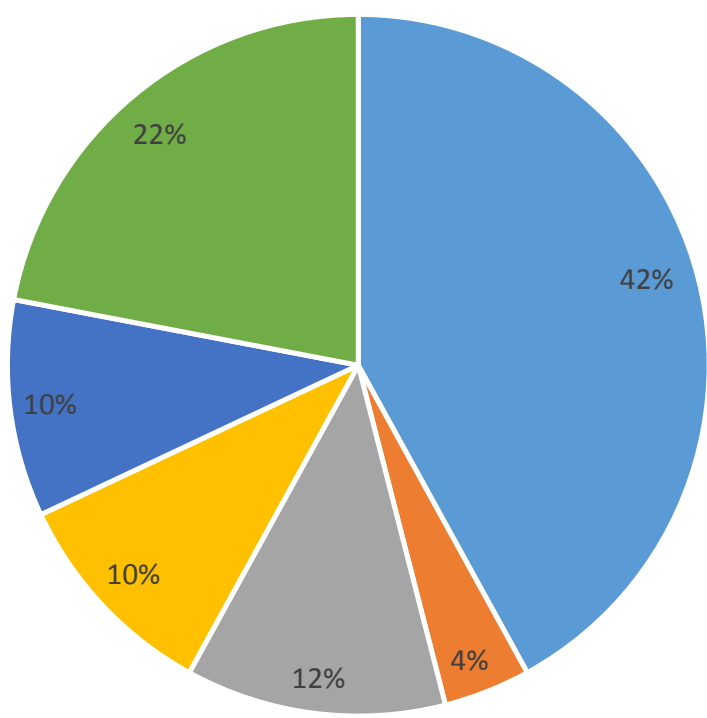

- Leaks

- Optimization of Overall Process

- Optimizaed Drive System

\author{
- Pressure Drop \\ - Heat Recovery \\ - Other Measures
}

Fig.2. Energy Savings Opportunities in Air Compressor Systems [25] 


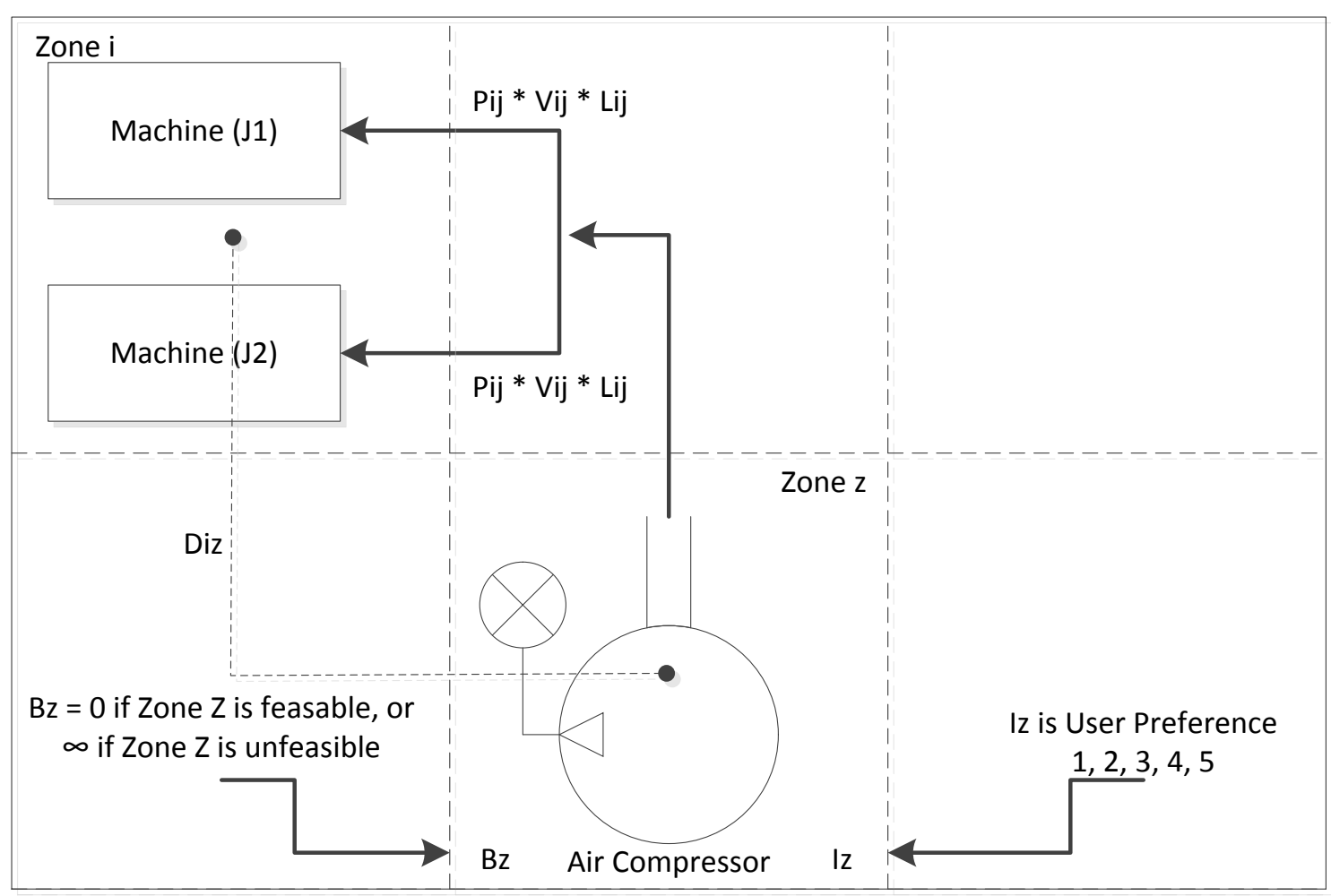

Fig.3. Air Compressor Set-up and Relationship of Variables in Optimization Model 


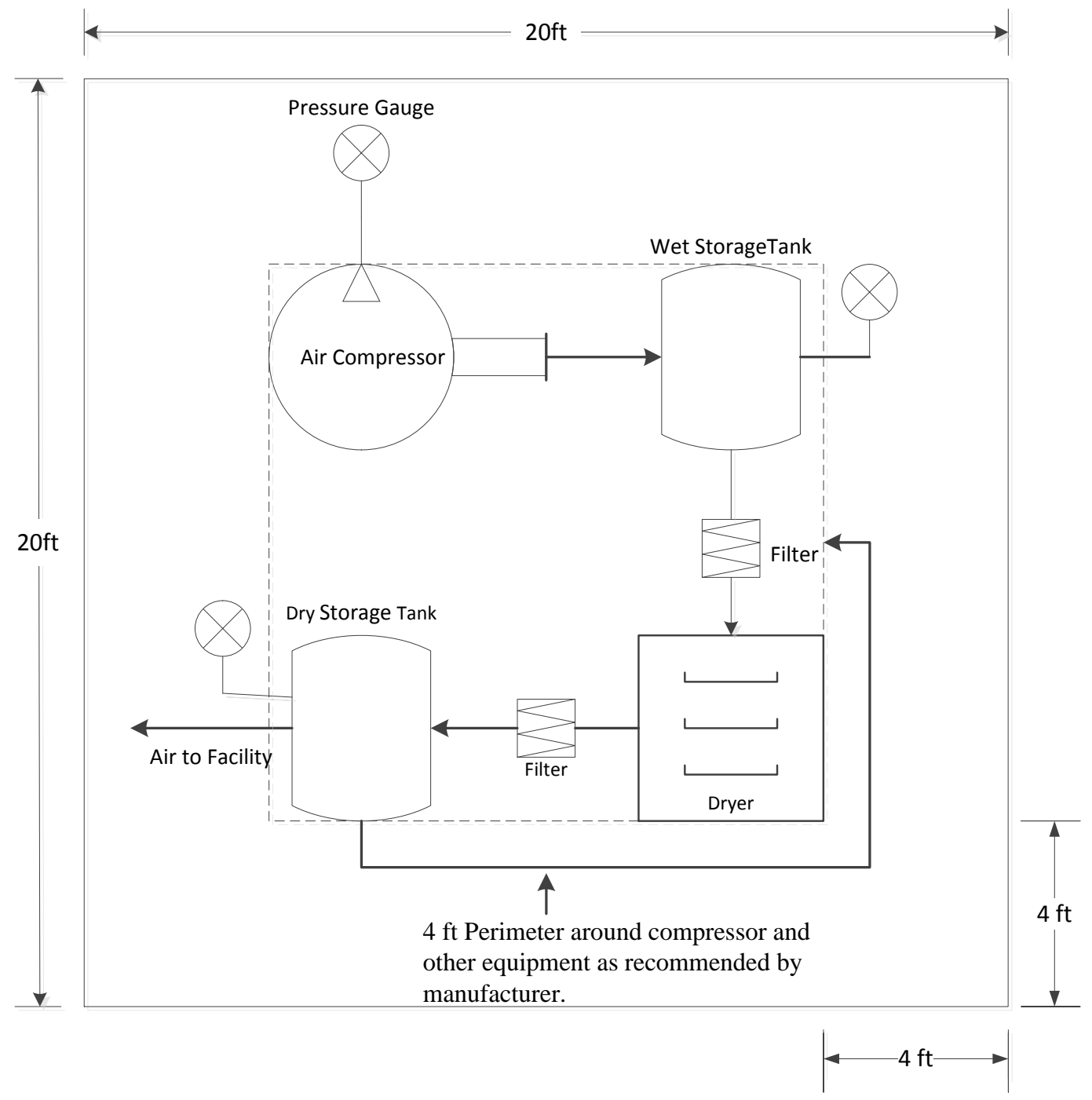

Fig.4. Typical Air Compressor Room Set-up and Foot Print 
Air Compressor at Zone 1 feeding to Zones $1 \rightarrow \mathrm{n}$

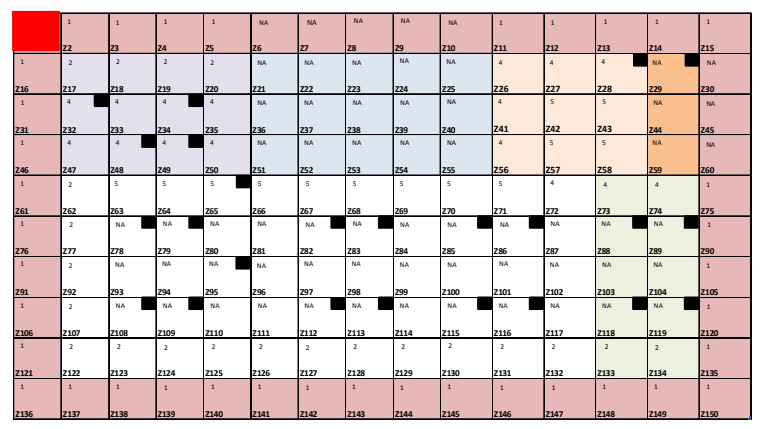

Air Compressor at Zone 3 feeding Zones $1 \rightarrow \mathrm{n}$

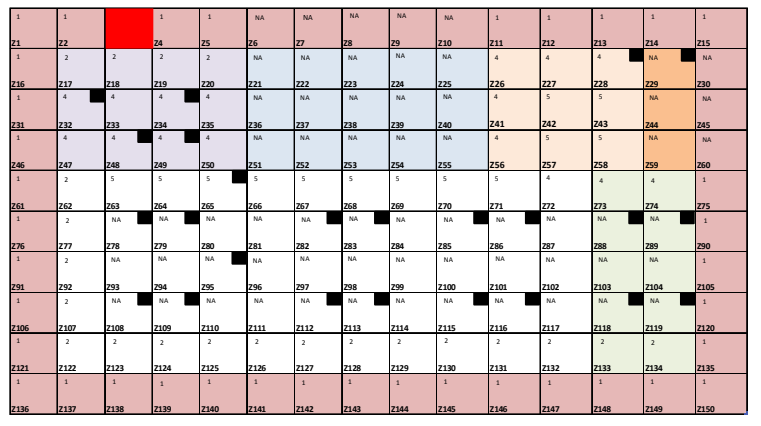

Air Compressor at Zone 2 feeding to Zones $1 \rightarrow \mathrm{n}$

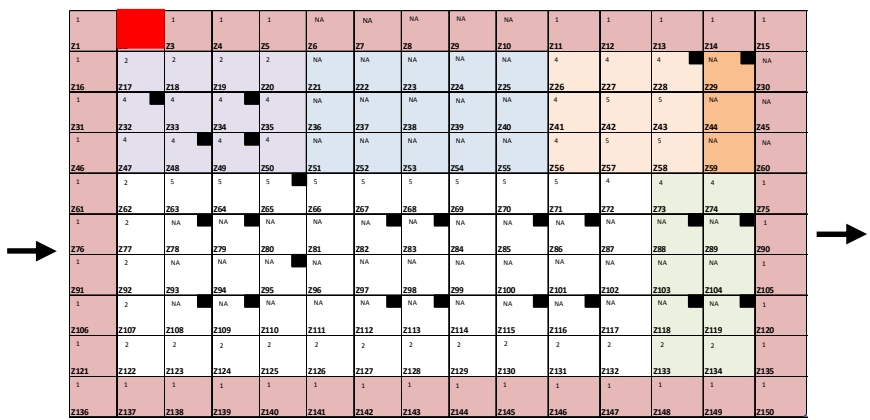

Air Compressor at Zone 150 feeding to Zones $1 \rightarrow \mathrm{n}$

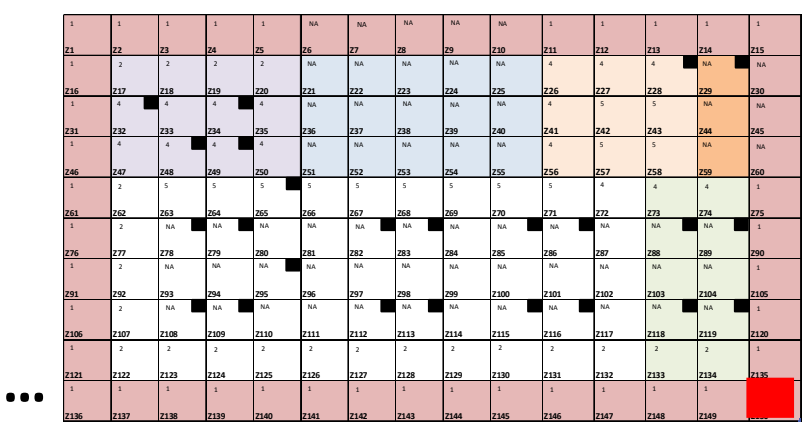

Fig.5. Graphical Representation of Simulation-Optimization Approach. 


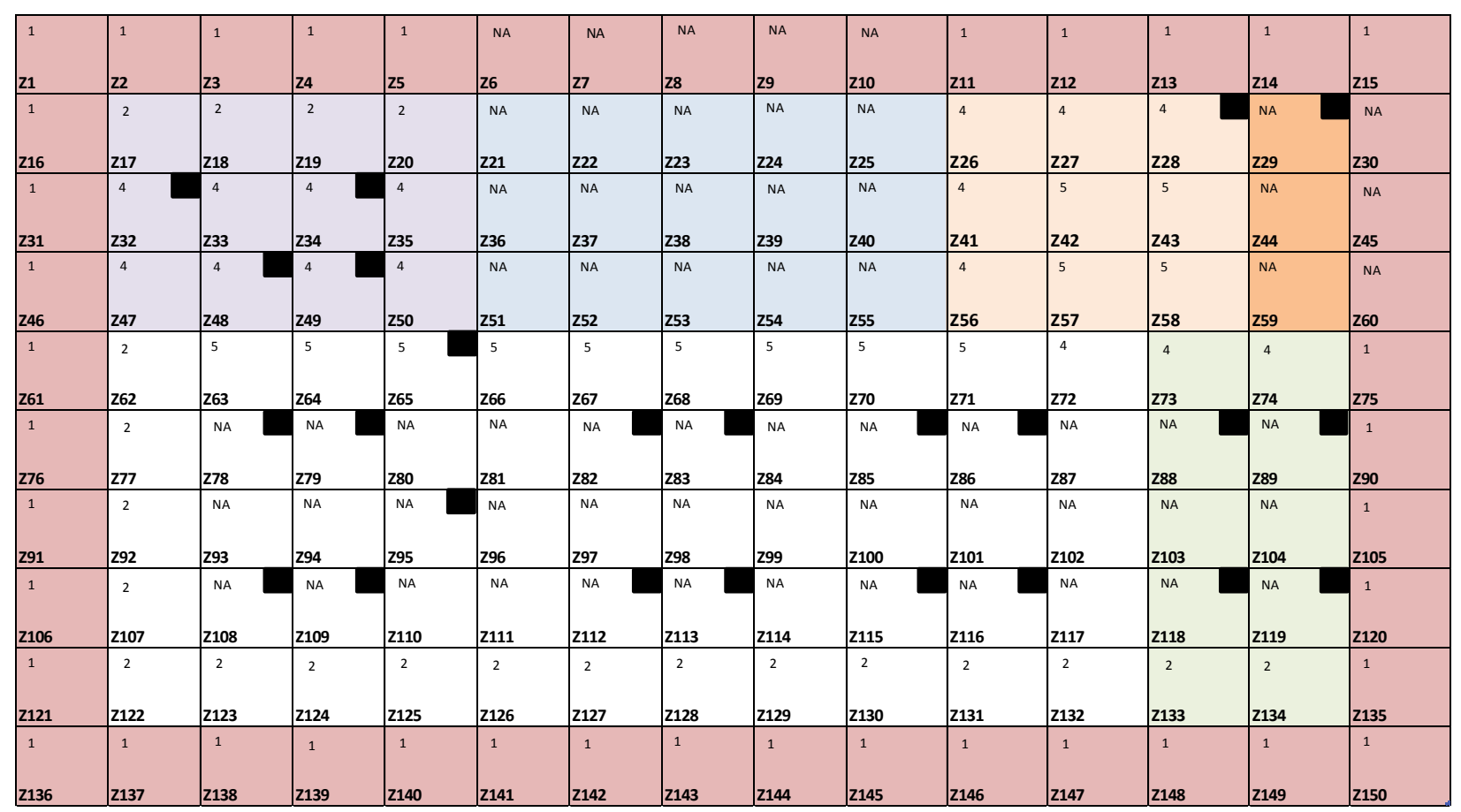

Outside Space:

Machine Shop:

Paint and Sandblasting Area:

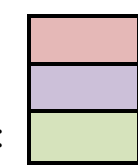

Office Space:

Warehouse Space:

Demand Zones
Production Area:

Shipping and Receiving:

User Preference

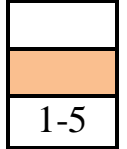




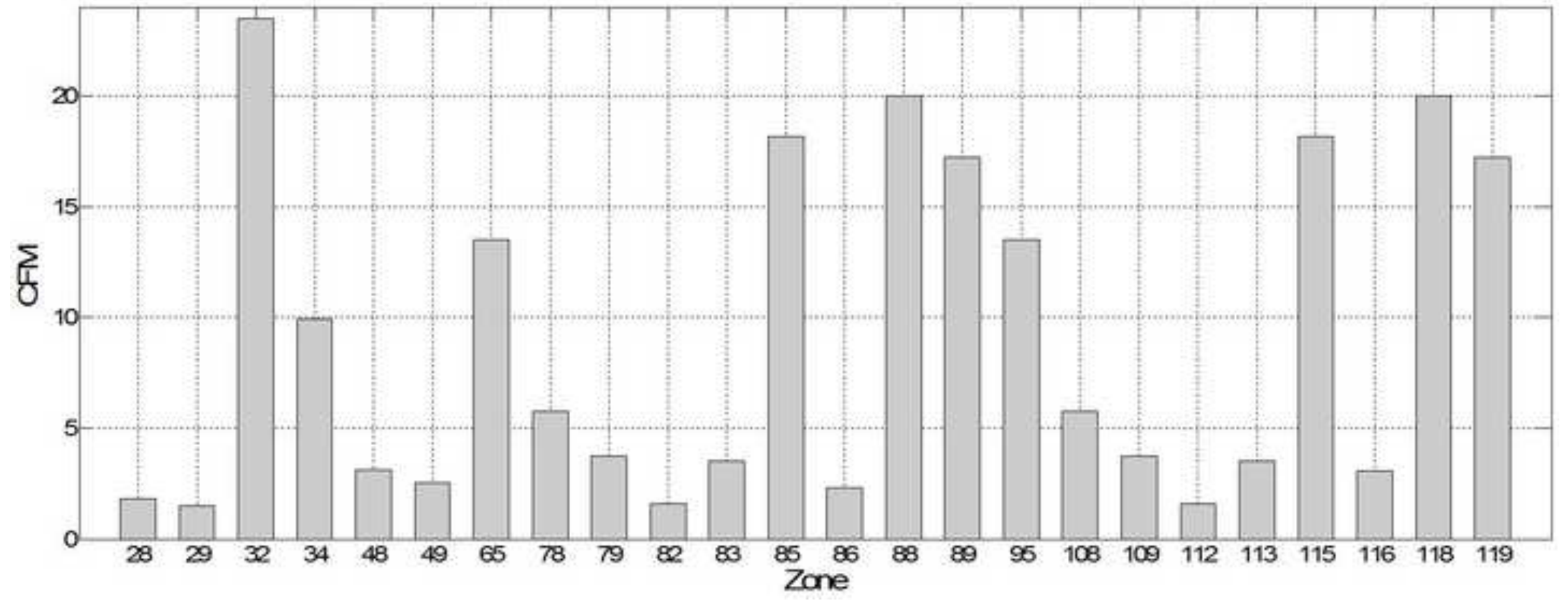

Page 39 of 49 


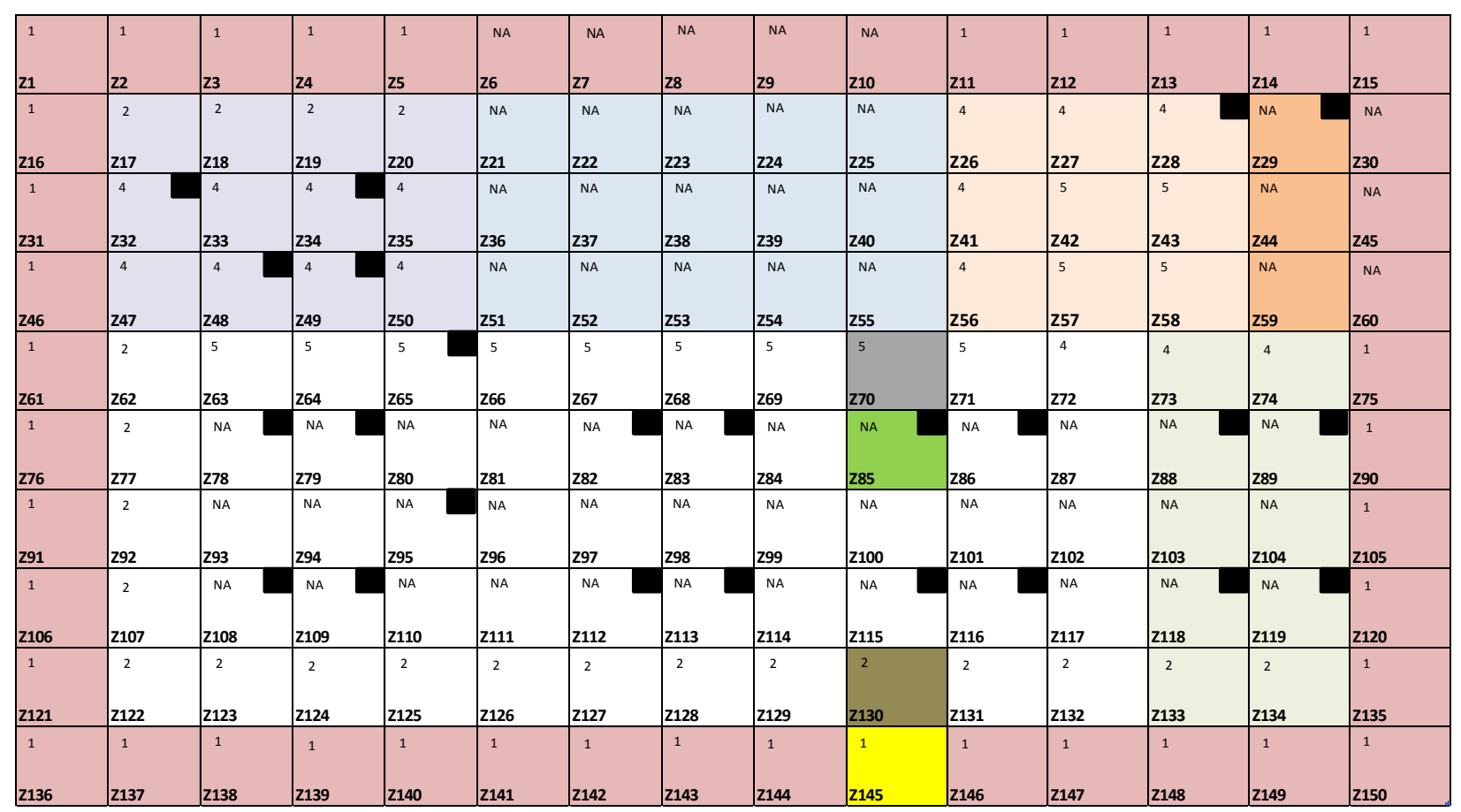

Outside Space:

Machine Shop:

Paint and Sandblasting Area:

Energy Efficient Zone:

Optimal Zone W 13-100\%
Office Space:

Warehouse Space:

Demand Zones

Optimal Zone $W$ 1-5\%
Production Area:

Shipping and Receiving:

User Preference

Optimal Zone W 6-12\%

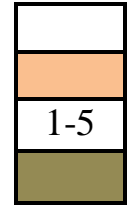




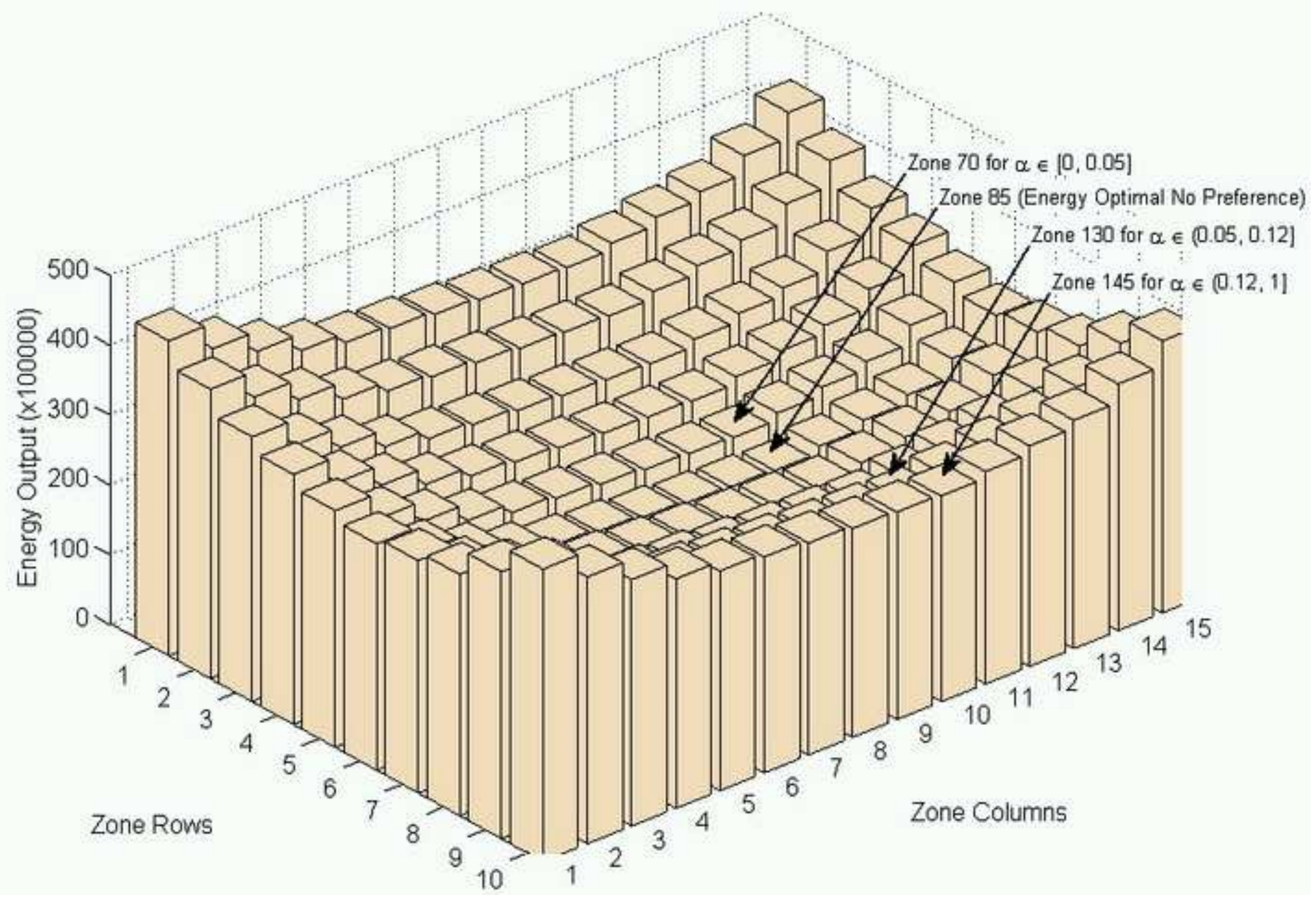




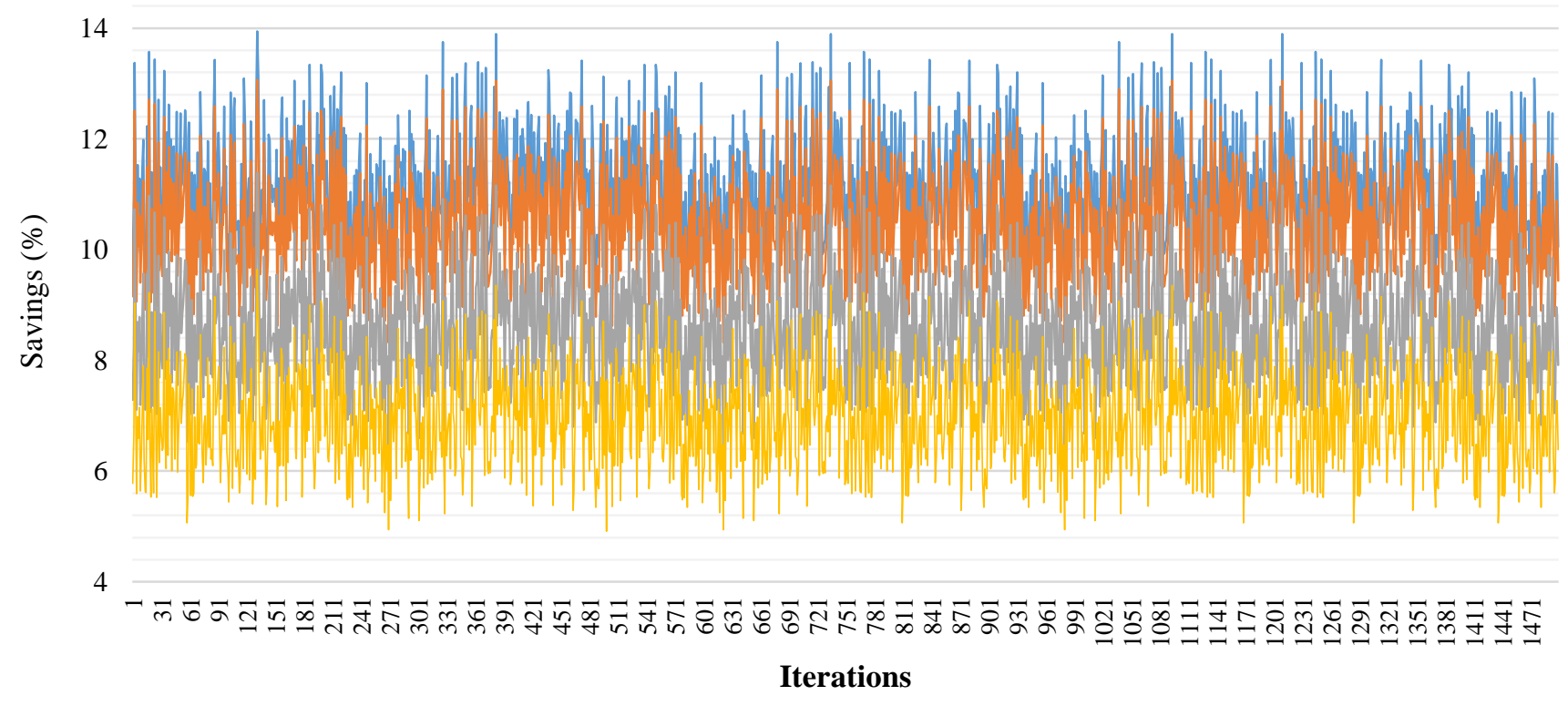

Fig. 10. Resulting Percent Savings Potential by each Model Iteration 


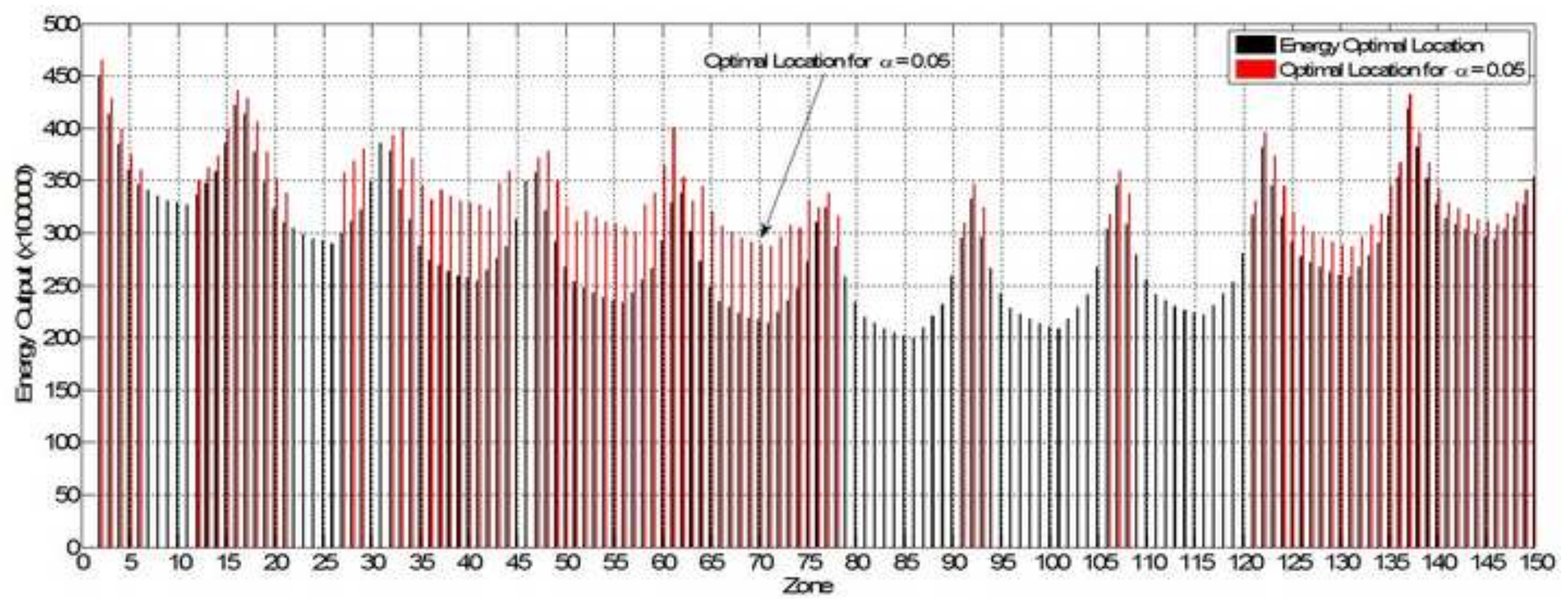




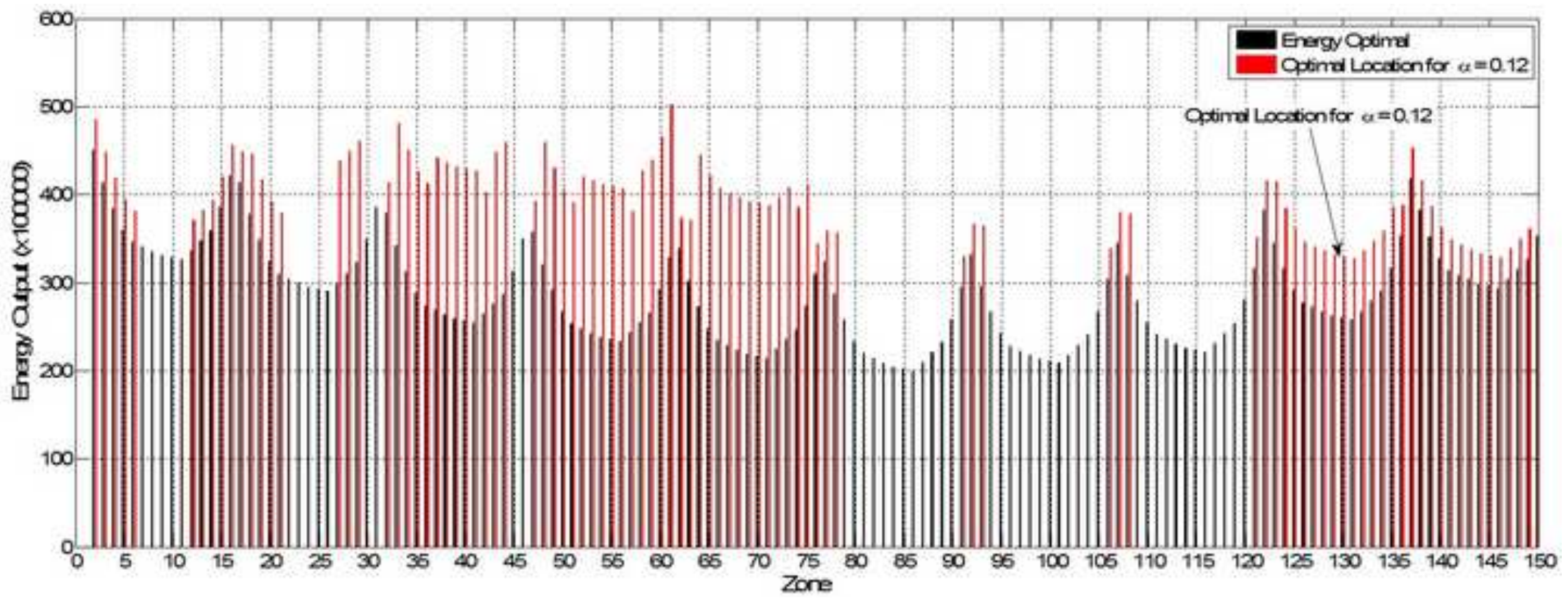




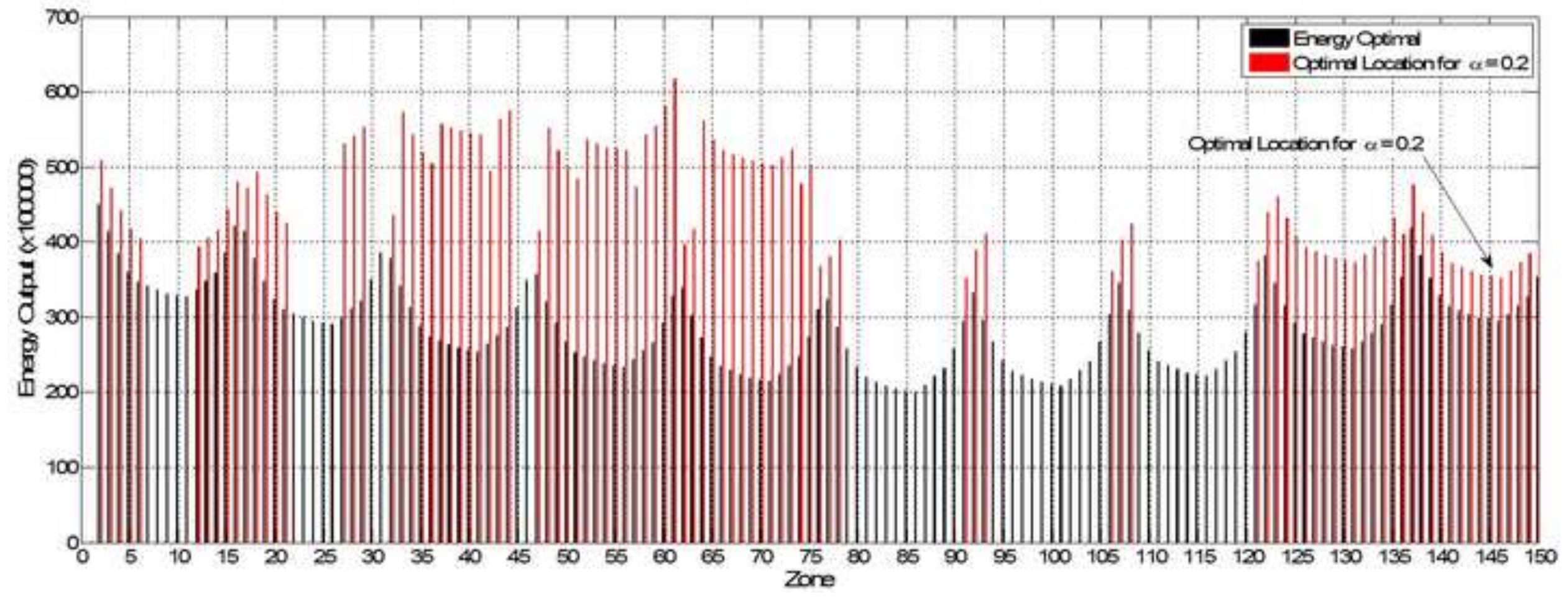




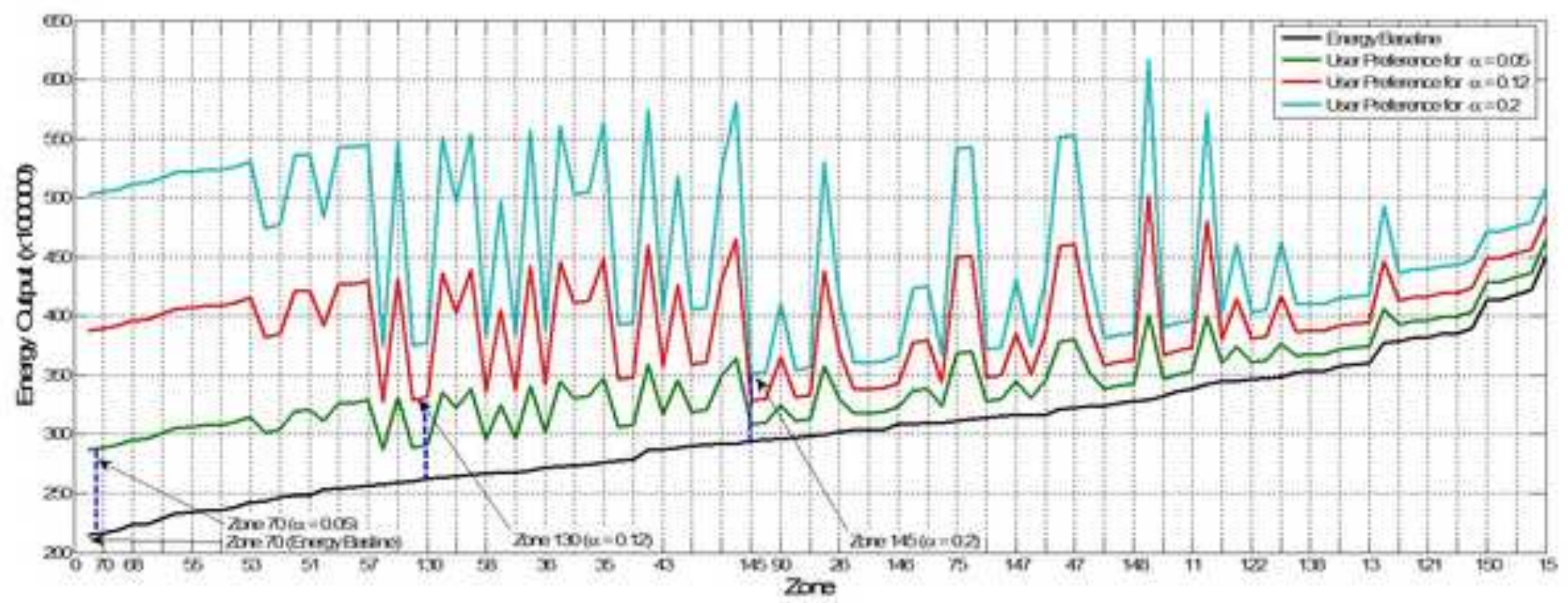


Table 1

Displays pressure (psi), load factor, and volume (cfm) for each individual machine, at each zone in the modeled facility.

\begin{tabular}{|c|c|c|c|c|c|c|c|c|c|}
\hline Zone & Machine & PSI & CFM & $\mathbf{L F}(\%)$ & Zone & Machine & PSI & CFM & $\mathbf{L F}(\%)$ \\
\hline \multirow[t]{2}{*}{$\mathrm{Z} 28$} & Nailer \#1 & 80 & 6 & $15 \%$ & $\mathrm{Z} 88$ & Sandblaster & 90 & 200 & $10 \%$ \\
\hline & Nailer \#2 & 80 & 6 & $15 \%$ & Z89 & Air Hoist & 80 & 5 & $20 \%$ \\
\hline \multirow[t]{2}{*}{ Z29 } & Stapler \#1 & 80 & 5 & $15 \%$ & & Paint Sprayer & 50 & 20 & $40 \%$ \\
\hline & Stapler \#2 & 80 & 5 & $15 \%$ & & Touch Up paint Gun & 90 & 4 & $15 \%$ \\
\hline \multirow[t]{3}{*}{$\mathrm{Z} 32$} & Drill \#1 & 70 & 60 & $20 \%$ & & Undercoat paint Gun & 90 & 19 & $40 \%$ \\
\hline & Drill \#2 & 85 & 50 & $20 \%$ & Z95 & Drill & 80 & 60 & $20 \%$ \\
\hline & Dusting Blow Gun & 80 & 5 & $30 \%$ & & Dusting Blow Gun & 80 & 5 & $30 \%$ \\
\hline \multirow[t]{3}{*}{$\mathrm{Z} 34$} & Dusting Blow Gun & 80 & 5 & $30 \%$ & $\mathrm{Z} 108$ & Impact Wrench & 80 & 10 & $30 \%$ \\
\hline & Grinder & 75 & 20 & $30 \%$ & & Screw Drivers & 90 & 5 & $15 \%$ \\
\hline & Vacuum Cleaner Shop & 100 & 6 & $40 \%$ & & Air Hoist & 80 & 5 & $40 \%$ \\
\hline \multirow[t]{2}{*}{$\mathrm{Z} 48$} & $\mathrm{CNC}$ & 80 & 8 & $20 \%$ & Z109 & Impact Wrench & 80 & 10 & $30 \%$ \\
\hline & Dusting Blow Gun & 80 & 5 & $30 \%$ & & Screw Drivers & 90 & 5 & $15 \%$ \\
\hline \multirow[t]{2}{*}{ Z49 } & Riveters & 90 & 12 & $15 \%$ & $\mathrm{Z} 112$ & Grease Gun & 70 & 4 & $20 \%$ \\
\hline & Screw Drivers & 90 & 5 & $15 \%$ & & Spring oiler & 50 & 4 & $20 \%$ \\
\hline \multirow[t]{2}{*}{ Z65 } & Drill & 80 & 60 & $20 \%$ & $\mathrm{Z} 113$ & Air Hoist & 80 & 5 & $40 \%$ \\
\hline & Dusting Blow Gun & 80 & 5 & $30 \%$ & & Dusting Blow Gun & 80 & 5 & $30 \%$ \\
\hline \multirow[t]{3}{*}{$\mathrm{Z78}$} & Impact Wrench & 80 & 10 & $30 \%$ & $\mathrm{Z} 115$ & Drill & 80 & 60 & $20 \%$ \\
\hline & Screw Drivers & 90 & 5 & $15 \%$ & & Impact Wrench & 80 & 10 & $30 \%$ \\
\hline & Air Hoist & 80 & 5 & $40 \%$ & & Screw Drivers & 90 & 5 & $15 \%$ \\
\hline \multirow[t]{2}{*}{$\mathrm{Z79}$} & Impact Wrench & 80 & 10 & $30 \%$ & & Vacuum Cleaner Shop & 100 & 6 & $40 \%$ \\
\hline & Screw Drivers & 90 & 5 & $15 \%$ & $\mathrm{Z} 116$ & Spring Oiler & 50 & 4 & $20 \%$ \\
\hline \multirow[t]{2}{*}{ Z82 } & Grease Gun & 70 & 4 & $20 \%$ & & Dusting Blow Gun & 80 & 5 & $30 \%$ \\
\hline & Spring oiler & 50 & 4 & $20 \%$ & & Screw Drivers & 90 & 5 & $15 \%$ \\
\hline \multirow[t]{2}{*}{ Z83 } & Air Hoist & 80 & 5 & $40 \%$ & $\mathrm{Z} 118$ & Sandblaster & 90 & 200 & $10 \%$ \\
\hline & Dusting Blow Gun & 80 & 5 & $30 \%$ & Z119 & Air Hoist & 80 & 5 & $20 \%$ \\
\hline \multirow[t]{4}{*}{ Z85 } & Drill & 80 & 60 & $20 \%$ & & Paint Sprayer & 50 & 20 & $40 \%$ \\
\hline & Impact Wrench & 80 & 10 & $30 \%$ & & Touch Up paint Gun & 90 & 4 & $15 \%$ \\
\hline & Screw Drivers & 90 & 5 & $15 \%$ & & Undercoat paint Gun & 90 & 19 & $40 \%$ \\
\hline & Vacuum Cleaner Shop & 100 & 6 & $40 \%$ & & & & & \\
\hline \multirow[t]{2}{*}{ Z86 } & Spring Oiler & 50 & 4 & $20 \%$ & & & & & \\
\hline & Dusting Blow Gun & 80 & 5 & $30 \%$ & & & & & \\
\hline
\end{tabular}


Table 2.

Results of simulation-driven analysis. Table 2 displays the probability of correct selection of the optimal zones, the range of savings and average savings for all iterations of the model. Note that Zone 85 and 83 are optimal with no articulation of user preference.

\begin{tabular}{|c|c|c|c|c|c|c|c|c|c|}
\hline & \multirow[b]{2}{*}{ Zone } & \multicolumn{3}{|c|}{ Optimal } & \multicolumn{4}{|c|}{ Alternative } & \multirow[b]{2}{*}{$\begin{array}{c}\text { Difference in Avg. } \\
\text { Savings (\%) }\end{array}$} \\
\hline & & $\begin{array}{c}\text { Probability } \\
(\%)\end{array}$ & $\begin{array}{l}\text { Range } \\
(\%)\end{array}$ & $\begin{array}{c}\text { Average } \\
(\%)\end{array}$ & Zone & $\begin{array}{c}\text { Probability } \\
(\%)\end{array}$ & $\begin{array}{l}\text { Range } \\
(\%)\end{array}$ & $\begin{array}{c}\text { Average } \\
(\%)\end{array}$ & \\
\hline $\begin{array}{l}\text { Energy Optimal } \\
\text { No Preference }\end{array}$ & 85 & 95.2 & 8.59-13.94 & 10.97 & 83 & 4.8 & $8.59-13.25$ & 10.905 & 0.065 \\
\hline $\begin{array}{c}\text { Optimal for } \alpha \in \\
{[0,0.05]}\end{array}$ & 70 & 97.3 & $8.03-13.06$ & 10.31 & 71 & 2.7 & $7.96-12.65$ & 10.43 & 0.12 \\
\hline $\begin{array}{l}\text { Optimal for } \\
\alpha \in(0.05,0.13]\end{array}$ & 130 & 96.7 & $6.27-11.38$ & 8.34 & 129 & 3.3 & $6.03-11.15$ & 8.39 & 0.05 \\
\hline $\begin{array}{l}\text { Optimal for } \alpha \in \\
(0.13,1]\end{array}$ & 145 & 99.1 & $4.91-9.64$ & 6.28 & 146 & 0.9 & 4.89-9.47 & 6.41 & 0.13 \\
\hline
\end{tabular}


Table 3.

Summary of Validation Results for the Eight Selected Zones. Table 2 displays the resulting air leaks, pressure drop (psi and \%), horsepower (theoretical and effective), and energy consumption $(\mathrm{kW})$ at each zone. Horsepower $(\mathrm{hp})$ is converted to kilowatt $(\mathrm{kW})$ using the conversion ratio of 1 hp to $0.746 \mathrm{~kW}$.

\begin{tabular}{lcccccccc}
\hline & Zone 1 & Zone 70 & Zone 76 & Zone 85 & Zone 96 & Zone 104 & Zone 130 & Zone 145 \\
\hline Leak (cfm) & 16.70 & 8.3 & 11.65 & 7.60 & 7.78 & 10.80 & 9.77 & 11.2 \\
Pressure Drop (psi) & 28.44 & 13.16 & 19.02 & 11.99 & 12.19 & 17.57 & 15.74 & 18.3 \\
Pressure Drop (\%) & 14 & 6.58 & 10 & 6 & 6 & 9 & 8 & 9.14 \\
Theoretical Horsepower & 41.70 & 40.2 & 40.79 & 40.06 & 40.09 & 40.64 & 40.45 & 40.71 \\
Effective Horsepower & 47.63 & 42.8 & 44.67 & 42.46 & 42.54 & 44.21 & 43.63 & 44.43 \\
Energy Consumption (kW) & 35.53 & 31.9 & 33.32 & 31.68 & 31.73 & 32.98 & 32.55 & 33.14 \\
\hline
\end{tabular}

